\title{
Bioinformatic characterisation of genes encoding cell wall degrading enzymes in the Phytophthora parasitica genome
}

\author{
Leila M Blackman ${ }^{1 *}$, Darren P Cullerne ${ }^{1,2}$ and Adrienne R Hardham ${ }^{1}$
}

\begin{abstract}
Background: A critical aspect of plant infection by the majority of pathogens is penetration of the plant cell wall. This process requires the production and secretion of a broad spectrum of pathogen enzymes that target and degrade the many complex polysaccharides in the plant cell wall. As a necessary framework for a study of the expression of cell wall degrading enzymes (CWDEs) produced by the broad host range phytopathogen, Phytophthora parasitica, we have conducted an in-depth bioinformatics analysis of the entire complement of genes encoding CWDEs in this pathogen's genome.

Results: Our bioinformatic analysis indicates that $431(2 \%)$ of the 20,825 predicted proteins encoded by the $P$. parasitica genome, are carbohydrate-active enzymes (CAZymes) involved in the degradation of cell wall polysaccharides. Of the 431 proteins, 337 contain classical N-terminal secretion signals and 67 are predicted to be targeted to the non-classical secretion pathway. Identification of CAZyme catalytic activity based on primary protein sequence is difficult, nevertheless, detailed comparisons with previously characterized enzymes has allowed us to determine likely enzyme activities and targeted substrates for many of the P. parasitica CWDEs. Some proteins (12\%) contain more than one CAZyme module but, in most cases, multiple modules are from the same CAZyme family. Only 12 P. parasitica CWDEs contain both catalytically-active (glycosyl hydrolase) and non-catalytic (carbohydrate binding) modules, a situation that contrasts with that in fungal phytopathogens. Other striking differences between the complements of CWDEs in P. parasitica and fungal phytopathogens are seen in the CAZyme families that target cellulose, pectins or $\beta-1,3-g l u c a n s$ (e.g. callose). About 25\% of $P$. parasitica CAZymes are solely directed towards pectin degradation, with the majority coming from pectin lyase or carbohydrate esterase families. Fungal phytopathogens typically contain less than half the numbers of these CAZymes. The P. parasitica genome, like that of other Oomycetes, is rich in CAZymes that target $\beta$-1,3-glucans.

Conclusions: This detailed analysis of the full complement of $P$. parasitica cell wall degrading enzymes provides a framework for an in-depth study of patterns of expression of these pathogen genes during plant infection and the induction or repression of expression by selected substrates.
\end{abstract}

Keywords: CAZymes, Carbohydrate binding module, Carbohydrate esterase, Cell wall degrading enzymes, Glycoside hydrolase, Polysaccharide lyase, Phytophthora parasitica genome

\footnotetext{
* Correspondence: leila.blackman@anu.edu.au

'Plant Science Division, Research School of Biology, College of Medicine, Biology and Environment, The Australian National University, Canberra ACT 0200, Australia

Full list of author information is available at the end of the article
}

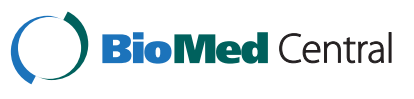

(c) 2014 Blackman et al.; licensee BioMed Central Ltd. This is an Open Access article distributed under the terms of the Creative Commons Attribution License (http://creativecommons.org/licenses/by/4.0), which permits unrestricted use, distribution, and reproduction in any medium, provided the original work is properly credited. The Creative Commons Public Domain Dedication waiver (http://creativecommons.org/publicdomain/zero/1.0/) applies to the data made available in this article, unless otherwise stated. 


\section{Background}

The ability to penetrate the formidable physical barrier of the plant cell wall is fundamental to successful pathogen invasion of plants and is facilitated by the secretion of cell wall degrading enzymes (CWDEs) by the pathogen. These extracellular effectors degrade a wide range of complex and cross-linked polysaccharides and glycoproteins. Pathogen CWDEs function not only in plant penetration but also in the release of nutrients for pathogen use. They are important determinants of pathogenicity [e.g. NCBI: NP_521723 and NP_522144; [1]].

The intricate, interconnected molecular network that constitutes the plant cell wall is centred around three types of polysaccharides: cellulose, hemicellulose and pectin [2]. Cellulose microfibrils consist of 30 to $50 \beta-1,4-$ linked glucan chains held together by intramolecular and intermolecular hydrogen bonds to form an insoluble scaffold [3]. Cellulose microfibrils are further cross-linked by hydrogen bonds to hemicellulose molecules and both are embedded in a pectin matrix. Hemicelluloses have a backbone of $\beta$-1,4-linked glucose, xylose, mannose and, sometimes, galactose units that are substituted with different side chains whose residues may be modified by the addition of acetyl or methyl groups [4-6]. Xyloglucans are the most abundant hemicellulose and consist of four subunits containing $\beta$-1,4-linked glucan backbones substituted with $\alpha-1,6$-xylosyl, $\beta$-1,2-galactosyl and $\alpha-1,2$ fucosyl residues in a variety of combinations $[3,4]$.

The most structurally diverse group of wall polysaccharides is the pectins [7]. The three main forms of pectin are homogalacturonan (HG), rhamnogalacturonan I (RGI) and rhamnogalacturonan II (RGII). HG is the simplest and most common form of pectin in plant cell walls. It consists of chains of $\alpha$-1,4-linked-D-galacturonic acid residues which are secreted in a methyl esterified form and which may also be acetylated at the O-2 and O-3 positions $[4,8]$. Cross-linking of unmethylesterified HG by calcium allows close packing of the HG chains and gives pectin its gel-like properties [3]. RGI polysaccharides consist of a backbone of $\alpha$-1,2-rhamnosyl and $\alpha-1,4$-galacturonic acid residues [5,9]. The rhamnosyl residues may be substituted with side chains having a diversity of lengths and compositions, including $\alpha$-linked arabinose residues (arabinans) and $\beta$-1,4-galactose linked $\alpha-1,3-\mathrm{L}$-arabinose residues (arabinogalactans), with some side chains also containing L-fucose and D-glucuronic acid residues [3,9]. $\alpha$-1,4-galacturonic acid residues in the backbone may be acetylated. RGII is a highly complex polysaccharide present as dimers linked by a borate ester with backbones of at least seven $\alpha$-1,4-linked galacturonic acid residues with a diversity of substitutions that are yet to be characterized [10].

Structural and biochemical properties of plant cell walls vary between dicotyledons and monocotyledons.
For example, $\beta-1,3: 1,4$-linked glucans are found only in grasses [6]. Plant cell walls also contain proteins and glycoproteins that may cross-link wall polysaccharides, thus strengthening the wall. They often contain glycosylphosphatidyl inositol (GPI) anchors and may function in connection of the wall with the plasma membrane. In glycoproteins, diverse carbohydrate chains are attached via the $\mathrm{N}$ in asparagine ( $N$-linked oligosaccharides), by the $\mathrm{O}$ in serine/threonine (O-linked oligosaccharides) or by hydroxyproline residues (arabinogalactan proteins: AGPs) [11]. In $N$-linked oligosaccharides, mannose and $\mathrm{N}$-acetylglucosamine residues form the backbone of the linked carbohydrate moiety [11]. In $O$-linked oligosaccharides, $N$-acetylgalactosamine residues form the carbohydrate backbone [12]. In AGPs, $\beta-1,3-$ and $\beta-1,6-$ galactose residues are joined to hydroxyproline and are substituted with many different saccharides including Lfucose, L-rhamnose and D-xylose [13].

The complex nature of cellulose, hemicellulose, pectins and glycoproteins and their interactions within the cell wall mean that the plant cell wall is a structurally diverse and effective barrier to plant pathogens $[2,14]$. Typically, plant cell wall structure and composition differs in different plant tissues and cell types [2] and changes during growth and development and in response to biotic and abiotic stress $[5,15]$. For example, $\beta$-1,3-glucans (callose) are often deposited at the site of pathogen invasion, creating, it is believed in at least some plant-pathogen interactions, a wall that is more resistant to pathogen penetration $[15,16]$.

Synthesis, modification and degradation of the complex carbohydrates that form plant cell walls require large numbers of highly specific enzymes [17]. The Arabidopsis thaliana genome, for example, contains 730 genes encoding proteins involved in these processes and the Aspergillus nidulans genome contains 224 genes for proteins specifically involved in wall degradation $[18,19]$. To aid research in this field, protein motifs that confer carbohydrate catalytic activity have been classified into sequence-related families of Carbohydrate-Active enZyme (CAZyme) modules [19]. These modules are divided into six classes - glycoside hydrolases (GHs), polysaccharide lyases (PLs), carbohydrate esterases (CEs), glycosyltransferases (GTs), auxiliary activities (AAs) and non-catalytic, carbohydrate-binding modules (CBMs) [20-22]. The activity of proteins within these classes has been annotated according to sequence homologies, protein folding and known enzyme activities [20]. Many CAZyme proteins contain a number of different modules, allowing them to target specific or divergent substrates [21,23-26].

Oomycetes, including Phytophthora species, are major plant pathogens worldwide. Like fungal phytopathogens, Oomycete species produce a wide range of cytoplasmic and extracellular effector proteins that facilitate their 
successful infection of host plants [27,28]. Over recent years, a number of Oomycete genomes have been sequenced, providing a wealth of information for studies of Oomycete effectors and pathogenicity mechanisms. Analyses of genomes from $P$. sojae, $P$. infestans, $P$. ramorum, Pseudoperonospora cubensis and Pythium species have catalogued CWDEs that contain CAZyme modules in these organisms [29-32], however, the regulation of CAZyme production and the role of individual CWDEs during plant infection remains largely unknown. The bioinformatic study reported in the present paper builds on the identification of CAZymes in these other Oomycetes to generate a comprehensive analysis of the complement of CWDEs in the broad host range pathogen, $P$. parasitica. Sequence and motif characterizations have been used to explore likely functions of individual $P$. parasitica CAZyme proteins. The study provides the framework for future studies of the expression of $P$. parasitica CWDEs during plant infection.

\section{Methods}

Identification of $P$. parasitica CWDEs

Predicted proteins were downloaded from the $P$. parasitica INRA-310 Sequencing Project [33] and screened for carbohydrate-active modules using Carbohydrate-active enzyme ANnotation [dbCAN, [34,35]. CAZyme module annotation by this program uses E-value, alignment length and coverage, with an E-value of $<1 \mathrm{e}-5$ for alignments of $>80$ amino acids and an E-value of $<1 \mathrm{e}-3$ for alignments of $<80$ amino acids. Proteins containing GT modules were identified but not included in further analysis. To eliminate proteins identified by dbCAN but that were not really CAZymes, proteins with CAZyme motifs with a dbCAN E-value > e-10 were individually examined using MyHits [36], Prosite [37,38] and BLASTp of non-redundant protein sequences in National Center for Biotechnology Information (NCBI) [39]. Proteins for which the alignment coverage was less than 0.5 , were also individually examined. Putative CWDEs were those identified as containing GH, PL, CE, CBM and AA modules that are known to be associated with the degradation of carbohydrates associated with the cell wall. To identify CWDEs that might have been missed by dbCAN, additional searches including keyword and Pfam [40,41] domain searches and tBLASTn analysis [42] with characterised proteins listed on the CAZy site [43] were conducted. When there was ambiguity in the identification of a CWDE, CAZymes Analysis Toolkit (CAT) $[44,45]$ was employed. Some proteins were also checked against data in the partially-completed Version 3 of the P. parasitica genome [46]. Transcripts identified by dbCAN that were predicted to have two unrelated functions were considered to be genome assembly errors and were not included in subsequent analysis. When a protein contained a CBM as well as a GH motif, the protein was classified according to the GH catalytic activity.

Because CAZyme annotation is based on sequence similarity rather than substrate specificity, enzymes that act on different substrates are placed within the same family and, conversely, enzymes acting on the same substrate are found in different families [26]. Where possible, the putative function of $P$. parasitica CAZymes has been deduced by comparisons with characterised proteins using BLAST analysis and identification of key catalytic residues. Classical signal peptides for secretion (SPs) were identified using SignalP $4.1[47,48]$ and proteins targeted to the nonclassical secretion pathway identified using SecretomeP 1.0f $[49,50]$. Pathogen CWDEs need to be secreted in order to function in wall degradation, however, putative CWDEs lacking an in silico-recognised SP were retained in the analysis because this in silico analysis is not $100 \%$ reliable $[51,52]$. For proteins where an SP was not detected, the $5^{\prime}$ end of the $P$. parasitica INRA-310 genomic sequence was manually examined for nearby alternative start codons. Transmembrane domains (TMD) were identified using Phobius [53] and TMHMM [54,55]. Potential GPI anchors were identified with PredGPI [56,57].

When a gene appeared to be truncated, the missing sequence data were sought in the immediate upstream or downstream region within the supercontig. Phytophthora EST data in NCBI and, in some cases, the orthologous coding region in other P. parasitica isolates (P1569, P1976, P10297 and CJ01A1) [33] were used to correct the INRA-310 isolate gene models. Where data from one of these other $P$. parasitica isolates has been used to modify an INRA-310 isolate gene sequence, the name of the source isolate is shown as a superscript above the INRA310 protein ID number from the Broad Institute sequencing project [33]. Protein similarities and identities were determined by multiple sequence and pairwise alignments of full-length proteins, omitting the SP if present [58,59]. Proteins were considered to be homologs if they shared $25 \%$ or more identity with an alignment length greater $>80$ amino acids [60].

\section{Results and discussion}

\section{Identification of CAZyme modules in P. parasitica} predicted proteins

A total of 750 CAZyme modules were identified in 671 of the 20,825 predicted proteins of $P$. parasitica using dbCAN (Additional file 1: Table S1). Of these, 240 proteins were eliminated from further analysis because they either contained a GT module (151 proteins) or were CAZymes that would function intracellularly. BLAST searches identified 19 additional putative CWDEs that had carbohydrate-active domains recognised by Pfam27.0 and other protein motif analysis programmes but not by dbCAN. The total of 431 putative CWDE proteins were 
classified into $14 \mathrm{CBM}, 34 \mathrm{GH}$, eight $\mathrm{CE}$, three PL and four AA families (Tables 1, 2, 3, Additional file 2: Table S2). Two CBM modules (CBM25 and CBM43) occurred only in conjunction with a GH module and were included in the GH family. Analysis of these $431 \mathrm{P}$. parasitica proteins showed that 327 contained a classical N-terminal SP, 67 contained non-classical secretion sequences, 70 contained a TMD and 31 contained a GPI anchor sequence.

$P$. parasitica proteins with multiple CAZyme modules were relatively rare, with only 50 of the 431 proteins (i.e., 11.6\%) having more than one module. In 37 cases, the protein contained two or more copies of the same CAZyme module. These included 29 proteins with two GH16, CBM1 or PL1 modules and three proteins with either three or six CBM13 modules. In the other 13 cases, the protein contained two CAZyme modules of different types. In plants and fungi, $\mathrm{CE}$ and $\mathrm{GH}$ modules are often accompanied by CBM modules [61,62]. As an example, only $4.3 \%$ of $P$. parasitica $\mathrm{GH}$ proteins also contained a CBM module whereas $15.5 \%$ of $\mathrm{GH}$ proteins from $A$. thaliana also have a CBM module [61].

CAZyme classification relies upon amino acid sequence but since tertiary structure and substrate binding is dependent upon primary structure, the substrate of many CWDEs can be inferred from the primary sequence data. However, it is possible for slight differences in protein folding arising from small variations in amino acid sequence to change the targetted substrate [63]. Where possible, sequence homology with characterized CAZymes has been used to group predicted CWDEs according to the substrate(s) they degrade.

\section{CAZymes involved in cellulose degradation}

The $\beta$-1,4-linked glucose residues that form cellulose can be degraded by enzymes that fall into four broad categories: endo- and exo- $\beta-1,4$-glucanases $[17,18,64]$, cellobiohydrolases $[64,65]$ and $\beta$-glucosidases [66]. There are also AA proteins that assist in cellulose breakdown through direct or indirect enzyme activity [21], and CBMs that bind to cellulose and act to concentrate enzyme activities. In some cases, CBMs may mediate non-catalytic disruption of the crystalline structure of cellulose, thereby facilitating degradation via catalytic modules [22]. In $P$. parasitica, CAZyme families containing exo- $\beta$-1,4-glucanases include $\mathrm{GH} 1$ and $\mathrm{GH} 3$ while families containing endo- $\beta$-1,4-glucanases include GH5, GH6, GH7, GH12 and GH131. Cellobiohydrolases are found in GH5, GH6 and $\mathrm{GH} 7$ and $\beta$-glucosidases occur in GH1, GH3 and $\mathrm{GH} 30$ families. Cellulose is not the sole substrate for many of the CAZymes in these families and hemicelluloses and pectins are often also targetted. $P$. parasitica AA proteins consist of two types of monooxygenases that cause direct oxidative cleavage (AA9 and AA10), and one family of reductases (AA8) that produce hydroxyl radicals resulting in the non-enzymatic breakdown of cellulose chains [21]. The genome also contains two CBM families that are specific for cellulose [22].

\section{Glycosyl hydrolases}

GH1, GH3 and GH30 families include enzymes that target disaccharides and the terminal non-reducing end of a range of polysaccharides (Figure 1) [18,64,66-68]. Fungal phytopathogens typically have small GH1 families [69-71] but in P. parasitica there are $17 \mathrm{GH} 1$ proteins, many of which contain conserved residues important for $\beta$-glucosidase activity [67]. It was not possible to determine specific enzyme activities of the $P$. parasitica $\mathrm{GH} 1$ proteins based on sequence homologies with characterized enzymes but 11 [PPTG_12005, 12006, 12007, 12009, 12010, 12011, 12051, 12052, 12102, 19353 and 19709] contained a TMD in the C-terminal region and overall share 29\% amino acid identity (Additional file 2: Table S2). The implied membrane-anchorage may be indicative of a role of these enzymes in the modification of Phytophthora rather than of host cell walls. For example, A. thaliana contains plasma membrane located $\beta$-glucosidases from both GH1 and GH3 families and they are thought to act in the production and modification of the plant cell wall [72]. TMDs have been found in some fungal GH9 $\beta$-glucanases from the basidiomycete, Phanerochaete chrysosporiumi, and in plant proteins containing GH9 modules that are involved in plant cell wall modification $[73,74]$.

GH3 is the third largest CAZyme family in $P$. parasitica with 25 members (Table 1). Many fungal phytopathogens also have large GH3 families [69-71]. GH3 proteins act on disaccharides and on the non-reducing end of a range of polysaccharides to release single residues such as glucose or xylose (Figures 1 and 2) [64]. GH3 proteins may also be involved in the degradation and processing of AGPs [64]. An alignment of 17 similar-sized $P$. parasitica GH3 proteins showed that they had little overall homology (3\%) but these proteins could be grouped into four subfamilies, with members of each subfamily sharing $24,38,46$ or $55 \%$ amino acid identity. Comparisons with enzymes with known activities did not provide any clues as to the specific substrate of each GH3 subfamily.

Fungal GH30 families contain only a few members whereas most Oomycetes sequenced to date have large GH30 families [31,69-71]. P. parasitica contains 21 predicted GH30 proteins. Sequence alignments allowed the $P$. parasitica GH30 family to be divided into three subfamilies. The sequences of $10 P$. parasitica proteins [PPTG_03369, 07665, 09210, 09211, 09212, 09214, 09215, 09216, 09217 and 14237] in one subfamily were similar to an $85 \mathrm{kDa} \beta$-glucosidase/xylosidase from $P$. infestans designated BGX1, with one protein, PPTG_09215, sharing 
Table $1 P$. parasitica proteins containing glycosyl hydrolase (GH) modules

\begin{tabular}{|c|c|c|c|c|c|}
\hline $\begin{array}{l}\text { CAZyme } \\
\text { family }\end{array}$ & Substrate & Enzyme activity & $\begin{array}{l}\text { EC } \\
\text { number }\end{array}$ & Number & References \\
\hline \multirow[t]{4}{*}{$\mathrm{GH} 1$} & cellulose & $\beta$-glucosidase & 3.2.1.21 & 17 & $\begin{array}{l}18,64,66 \\
67\end{array}$ \\
\hline & hemicellulose (xyloglucans) & exo- $\beta$-1,4-glucanase & $3.2 \cdot 1.74$ & & $72-74$ \\
\hline & pectin (RGI) & $\beta$-galactosidase & 3.2.1.23 & & \\
\hline & & $\beta$-mannosidase & 3.2.1.25 & & \\
\hline \multirow[t]{2}{*}{$\mathrm{GH} 2$} & hemicellulose (mannans) & $\beta$-mannosidase & 3.2 .1 .25 & 1 & 64 \\
\hline & glycoproteins (mannans) & & & & \\
\hline \multirow[t]{5}{*}{$\mathrm{GH} 3$} & cellulose & $\beta$-glucosidase & 3.2.1.21 & 25 & 64,97 \\
\hline & pectin (RGI) & exo- $\beta-1,4-g l u c o s i d a s e$ & 3.2.1.74 & & \\
\hline & hemicellulose (xyloglucans) & xylan $\beta$-1,4-xylosidase & 3.2.1.37 & & \\
\hline & AGPs & glucan $\beta$-1,3-glucosidase & 3.2 .1 .58 & & \\
\hline & & a-L-arabinofuranosidase & 3.2.1.55 & & \\
\hline \multirow[t]{5}{*}{ GH5 } & cellulose & endo- $\beta$-1,4-glucanase & 3.2.1.4 & 22 & $\begin{array}{l}23,64,76 \\
97\end{array}$ \\
\hline & hemicellulose (xylans) & $\beta$-1,4-cellobiosidase & 3.2.1.91 & & \\
\hline & hemicellulose (galactomannans) & endo- $\beta-1,4$-xylanase & 3.2.1.8 & & \\
\hline & $\beta$-1,3-glucans & endo- $\beta-1,4-m a n n o s i d a s e$ & 3.2 .1 .78 & & \\
\hline & & glucan $\beta$-1,3-glucosidase & 3.2 .1 .58 & & \\
\hline GH5/CBM43 & $\beta$-1,3-glucans & glucan $\beta-1,3$-glucosidase & 3.2.1.58 & 3 & 23,78 \\
\hline \multirow[t]{2}{*}{ GH6 } & cellulose & endo- $\beta$-1,4-glucanase & 3.2.1.4 & 7 & 18,79 \\
\hline & & cellobiohydrolase & 3.2.1.91 & & \\
\hline \multirow[t]{2}{*}{$\mathrm{GH} 7$} & cellulose & endo- $\beta$-1,4-glucanase & 3.2.1.4 & 5 & 77,80 \\
\hline & & reducing end-acting cellobiohydrolases & 3.2.1.176 & & \\
\hline $\mathrm{GH} 10$ & hemicellulose (xylans) & endo- $\beta-1,4-\beta$-xylanase & 3.2.1.8 & 4 & 97 \\
\hline \multirow[t]{2}{*}{$\mathrm{GH} 12$} & cellulose & endo- $\beta$-1,4-glucanase & 3.2.1.4 & 15 & $\begin{array}{l}18,66,81 \\
82\end{array}$ \\
\hline & hemicellulose (xyloglucans) & xyloglucan endo- $\beta-1,4$-glucanase & 3.2.1.151 & & \\
\hline \multirow[t]{2}{*}{$\mathrm{GH} 13$} & starch & a-amylase & 3.2.1.1 & 1 & 141 \\
\hline & & a-glucosidase & 3.2 .1 .20 & & \\
\hline \multirow[t]{2}{*}{ GH13/CBM25 } & starch & a-amylase & 3.2.1.1 & 1 & 141 \\
\hline & & a-glucosidase & 3.2.1.20 & & \\
\hline \multirow[t]{2}{*}{$\mathrm{GH} 16$} & hemicellulose (xyloglucans) & xyloglucan endo- $\beta$-1,4-glucanase & 3.2.1.151 & 25 & $94-96$ \\
\hline & $\beta$-1,3-glucans & $\beta$-1,3-glucosidase & 3.2.1.39 & & \\
\hline $\mathrm{GH} 17$ & $\beta$-1,3-glucans & endo- $\beta-1,3-$ glucosidase & 3.2.1.39 & 17 & 39 \\
\hline GH17/CBM13 & $\beta$-1,3-glucans & endo- $\beta$-1,3-glucosidase & 3.2 .1 .39 & 3 & 22,88 \\
\hline $\mathrm{GH} 18$ & $\mathrm{~N}$-linked oligosaccharides & endo- $\beta-N$-acetylglucosaminidase & 3.2 .1 .96 & 3 & 64,132 \\
\hline GH19 & N-linked oligosaccharides & endo- $\beta-\mathrm{N}$-acetylglucosaminidase & 3.2.1.14 & 2 & 64 \\
\hline $\mathrm{GH} 28$ & pectin $(H G)$ & polygalacturonase & 3.2.1.15 & 18 & 111,112 \\
\hline \multirow[t]{5}{*}{$\mathrm{GH} 30$} & cellulose & $\beta$-glucosidase & 3.2.1.21 & 17 & $\begin{array}{l}18,64,66 \\
68\end{array}$ \\
\hline & hemicellulose (xyloglucans) & endo- $\beta-1,4$-xylanase & 3.2.1.8 & & 75,99 \\
\hline & pectin (RGI) & xylan $\beta$-1,4-xylosidase & 3.2.1.37 & & \\
\hline & AGPS & endo- $\beta-1,6-$ galactanase & 3.2.1.164 & & \\
\hline & & $\beta-1,6-$ glucanase & 3.2.1.75 & & \\
\hline
\end{tabular}


Table 1 P. parasitica proteins containing glycosyl hydrolase (GH) modules (Continued)

\begin{tabular}{|c|c|c|c|c|c|}
\hline GH30/CBM13 & hemicellulose (xyloglucans) & xylan $\beta$-1,4-xylosidase & 3.2 .1 .37 & 4 & 22,88 \\
\hline \multirow[t]{2}{*}{$\mathrm{GH} 31$} & starch & a-glucosidase & 3.2.1.20 & 9 & $18,143,144$ \\
\hline & hemicellulose (xyloglucans) & a-xylosidase & 3.2.1.177 & & \\
\hline GH31/CBM25 & starch & a-glucosidase & 3.2.1.20 & 1 & 18,92 \\
\hline $\mathrm{GH} 32$ & sucrose & invertase & 3.2.1.26 & 5 & 146,147 \\
\hline \multirow[t]{2}{*}{ GH35 } & hemicellulose (xyloglucans) & $\beta$-galactosidase & 3.2.1.23 & 1 & 115 \\
\hline & pectin $(H G) ; A G P s$ & exo- $\beta-1,4$-galactanase & 3.2.1.- & & \\
\hline $\mathrm{GH} 37$ & trehalose (a,a-1,1-glucans) & a,a-trehalase & 3.2 .1 .28 & 2 & 43 \\
\hline $\mathrm{GH} 38$ & $N$-linked oligosaccharides & a-mannosidase & 3.2.1.24 & 1 & 136 \\
\hline \multirow[t]{3}{*}{$\mathrm{GH} 43$} & hemicellulose (xylans) & a-L-arabinofuranosidase & 3.2.1.55 & 7 & 97,98 \\
\hline & pectin (RGl) & & & & \\
\hline & AGP & & & & \\
\hline GH47 & $\mathrm{N}$-linked oligosaccharides & a-mannosidase & 3.2 .1 .113 & 5 & 136 \\
\hline GH53 & pectin (RGI) & endo- $\beta-1,4-$ galactanase & 3.2.1.89 & 6 & 116 \\
\hline GH54 & pectin (RGl) & a-L-arabinofuranosidase & 3.2.1.55 & 1 & $97,117,118$ \\
\hline \multirow[t]{3}{*}{ GH63 } & $\mathrm{N}$-linked oligosaccharides & processing a-glucosidase & 3.2 .1 .106 & 1 & 137 \\
\hline & & a-1,3-glucosidase & 3.2.1.84 & & \\
\hline & & a-glucosidase & 3.2.1.20 & & \\
\hline $\mathrm{GH} 72$ & $\beta$-1,3-glucans & $\beta-1,3-$ glucanosyl-transglycosylase & 2.4.1.- & 14 & 130,131 \\
\hline GH78 & pectin (RGl) & a-L-rhamnosidase & 3.2.1.40 & 4 & 113 \\
\hline GH81 & $\beta-1,3-$ glucans & endo- $\beta$-1,3-glucanase & 3.2.1.39 & 16 & 127,128 \\
\hline GH85 & AGPs & endo- $\beta$ - $N$-acetylglucosaminidase & 3.2.1.96 & 1 & 138 \\
\hline GH89 & $\mathrm{N}$-linked oligosaccharides & a-N-acetylglucosaminidase & 3.2.1.50 & 2 & 43,139 \\
\hline GH105 & pectin (RGI) & unsaturated rhamnogalacturonyl hydrolase & 3.2.1.172 & 1 & 114 \\
\hline GH109 & O-linked oligosaccharides & a-N-acetylgalactosaminidase & 3.2.1.49 & 7 & 43 \\
\hline $\mathrm{GH} 123$ & O-linked oligosaccharides & $\begin{array}{l}\text { glycosphingolipid } \beta-\mathrm{N}- \\
\text { acetylgalactosaminidase }\end{array}$ & 3.2.1.- & 1 & 43 \\
\hline GH131 & $\begin{array}{l}\text { cellulose ( } \beta-1,4-\text { glucans) hemicellulose ( } \beta-1,4- \\
\text { glucans) }\end{array}$ & $\begin{array}{l}\text { exo- } \beta-1,3 / 1,6-\text { glucanase with endo- } \beta-1,4- \\
\text { glucanase }\end{array}$ & 3.2.1.- & 5 & 83 \\
\hline Total & & & & 280 & \\
\hline
\end{tabular}

Potential substrates, likely enzyme activities, EC number and the number of family members are shown. The accession numbers of proteins in each GH category are tabulated in Additional file 2. Assessments of likely substrates and enzyme activities were based on information provided in the cited references. HG = homogalacturonan; $\mathrm{AGP}=$ arabinogalactan protein; $\mathrm{RGI}=$ rhamnogalacturonan $\mathrm{I}$.

81\% identity [NCBI: AAK19754; [75]]. BGX1 releases terminal $\beta$-glucose residues, and to a lesser extent $\beta$-xylose residues, from artificial substrates, suggesting that this group of $P$. parasitica GH30 proteins is likely to be involved in the release of glucose residues from $\beta$-1,4-linked glucans in both cellulose and xyloglucans. The other two subfamilies of $P$. parasitica GH30 proteins act on hemicellulose and AGPs and will be dealt with in a later section.

The GH5 CAZyme family is diverse. It includes endo$\beta$-1,4-glucanases, $\beta$-1,4-cellobiosidases, endo- $\beta$-1,4-mannanases, exo- $\beta$-1,3-glucosidases, endo- $\beta$-1,6-galactanases and $\beta-1,6$-glucanases and is one of the largest $\mathrm{GH}$ families in many symbiotic, biotrophic, hemibiotrophic and necrotrophic fungi. For example, the biotroph Puccinia triticina contains 28 GH5 CAZymes [20\% of all GH
CAZymes; [71]], the hemibiotroph Colletotrichum higginsianum contains 22 GH5 CAZymes [6\% of all GH CAZymes; [70]] and the necrotroph Stagonospora nodorum contains 18 [6\% of all GH CAZymes; [70]]. In $P$. parasitica, GH5 is one of the two largest CWDE families. The 25 GH5 proteins (Table 1) represent $9 \%$ of $P$. parasitica GH CAZymes; similar numbers of GH5 proteins are found in other characterised Oomycete species $[31,76]$. All $P$. parasitica GH5 proteins are potentially secreted, three contain GPI anchors [PPTG_01140, 01151 and 03220] and 11 contain TMDs (Additional file 2: Table S2). Because the main microfibrillar component in cell walls of Phytophthora and other Oomycete species is cellulose [77], rather than chitin as in fungi, these membrane-anchored endoglucanases may be involved in 
Table 2 P. parasitica proteins containing auxiliary activity (AA) and carbohydrate-binding (CBM) modules

\begin{tabular}{|c|c|c|c|c|c|}
\hline CAZyme family & Substrate & Enzyme activity & EC number & Number & References \\
\hline \multirow[t]{2}{*}{ AA7 } & cellobiose & glucooligosaccharide oxidase & 1.1.3.- & 5 & 21,87 \\
\hline & chitin/glycoproteins & chitooligosaccharide oxidase & & & \\
\hline AA8 & cellulose & iron reductase domain & na & 3 & 21 \\
\hline AA9 & cellulose & copper-dependent monooxygenase & 1.- & 1 & $21,84-86$ \\
\hline AA10 & cellulose & copper-dependent monooxygenase & 1.- & 4 & $21,24,84,85$ \\
\hline Total & & & & 13 & \\
\hline CBM1 & cellulose & & & 17 & $22,30,90,93$ \\
\hline CBM9 & hemicellulose (xylans) & & & 1 & 92 \\
\hline CBM13 & hemicellulose (xylans) & & & 4 & 22,88 \\
\hline CBM18 & chitin/glycoproteins & & & 1 & 133 \\
\hline CBM20/CBM47 & starch/fucose & & & 1 & 78,142 \\
\hline CBM32 & galactose, PGA and $\beta$-galactosyl- $\beta-1,4-G \mid c N A c$ & & & 1 & 126 \\
\hline \multirow[t]{2}{*}{ CBM37 } & hemicellulose (xylans) & & & 1 & \\
\hline & cellulose & & & & 78 \\
\hline CBM38 & inulin-binding & & & 1 & 43 \\
\hline CBM40 & sialidases & & & 2 & 78 \\
\hline CBM47 & fucose binding & & & 3 & 78 \\
\hline CBM50 & chitin/glycoproteins & & & 3 & 133-135 \\
\hline CBM57 & domains associated with glycosidases & & & 1 & 43 \\
\hline CBM63 & cellulose & & & 12 & 22 \\
\hline Total & & & & 48 & \\
\hline
\end{tabular}

Potential substrates, likely enzyme activity, EC number and the number of family members are shown. References used to determine the potential activities of each family are shown. CBMs do not have catalytic activity. The details of each protein in each family are found in Additional file 2. PGA = polygalacturonic acid; GlcNAc = N-acetylglucosamine; na $=$ not available.

pathogen wall modification as proposed for fungal GH5_9 proteins [23]. Ten GH5 proteins appear to be endo- $\beta$-1,4-glucanases, including eight [PPTG_03844, 03845, 03846, 03847, 04558, 05786, 05787 and 05788] that are homologous to GH5_20 subfamily proteins from other Phytophthora species [23]. P. parastica GH5_20 proteins contain a TMD at the predicted N-terminus. Three GH5 proteins also contain a CBM43 module (Additional file 2: Table S2) and are similar to previously identified proteins in the Stamenophile-specific GH5_33 subfamily of exo- $\beta$-1,3-glucanases [e.g. NCBI: CBJ27054; [23]]. While not all members of this subfamily have a CBM43 module, its presence would provide affinity for $\beta$-1,3-glucans [78]. Six other GH5 proteins were identified as potential $\beta$-1,3-glucosidases [PPTG_01483, 11518, 13105, 16240, 16244 and 16244] but had limited homology to the GH5_33 proteins.

Endo- $\beta$-1,4-glucanase activity also occurs in GH6, GH7, GH12 and GH131 families (Figure 1). All seven $P$. parasitica GH6, five GH7, 14 full-length GH12 and all five GH131 proteins have features for non-classical secretion or signal peptides directing secretion. The GH6 proteins share many conserved residues, including those found in dual-action endoglucanase-cellobiohydrolases
[79]. GH6 enzymes act at the non-reducing end of the polysaccharide chain. The five $P$. parasitica GH7 proteins share $29 \%$ amino acid identity and contain the ExDxxE motif typical of the GH7 family [65]. The GH7 family includes cellobiohydrolases that release the disaccharide cellobiose from the reducing end of cellulose chains, endo- $\beta-1,4$-glucanases and $\beta-1,3-1,4$ glucanases. Sequence alignment showed that the GH7 proteins could be split into two subfamilies but specific functions could not be assigned to individual GH7 proteins, although two [PPTG_07012 and 07017] sharing 71\% amino acid identity showed sequence similarities with $\beta-1,3: 1,4$ glucanases from Bispora sp. [e. g. NCBI: ACT53749, [80]] and the other three showed more similarity to endoglucanases from Trichoderma reesei [65]. Using sequence data from two orthologous genes [PPTG_11504 $4^{\mathrm{P} 10297}$ and $16275^{\mathrm{P} 10297}$ ] from another $P$. parasitica isolate to predict full-length versions of truncated proteins in the INRA-310 isolate, the $14 \mathrm{P}$. parasitica GH12 proteins were shown to contain the six GH12 consensus boxes described in Goedegebuur et al. [81]. P. parasitica GH12 proteins shared $19-100 \%$ pairwise amino acid identity and this sequence diversity is similar to that seen in fungal GH12 endoglucanases [81]. While 
Table $3 P$. parasitica proteins containing carbohydrate esterase (CE) and polysaccharide lyase (PL) modules

\begin{tabular}{|c|c|c|c|c|c|}
\hline CAZyme family & Substrate & Enzyme activity & EC number & Number & References \\
\hline CE1 & hemicellulose & feruloyl esterase & 3.1 .1 .73 & 3 & $43,45,93,101$ \\
\hline CE2 & hemicellulose & acetyl xylan esterase & 3.1 .1 .72 & 1 & 100,102 \\
\hline CE3 & hemicellulose & acetyl xylan esterase & 3.1.1.72 & 1 & 100,103 \\
\hline \multirow[t]{2}{*}{ CE4 } & hemicellulose & acetyl xylan esterase & 3.1.1.72 & 2 & $100,104,105$ \\
\hline & $N$-linked oligosaccharides & peptidoglycan GlcNAc deacetylase & 3.5.1.- & & \\
\hline \multirow[t]{2}{*}{ CE5 } & hemicellulose & acetyl xylan esterase & 3.1.1.72 & 4 & $100,107-109$ \\
\hline & & cutinase & 3.1.1.74 & & \\
\hline CE8 & pectin $(H G)$ & pectin methylesterase & 3.1.1.11 & 15 & 18,123 \\
\hline \multirow[t]{2}{*}{ CE12 } & pectin (HG, RGl) & pectin and RGI acetylesterase & 3.1.1.- & 14 & 18,125 \\
\hline & & acetyl xylan esterase & 3.1.1.72 & & \\
\hline CE13 & pectin $(H G)$ & pectin acetylesterase & 3.1.1.- & 6 & 124 \\
\hline Total & & & & 46 & \\
\hline \multirow[t]{3}{*}{ PL1 } & pectin (HG) & pectate lyase & 4.2.2.2 & 21 & 119-121 \\
\hline & & exo-pectate lyase & 4.2.2.9 & & \\
\hline & & pectin lyase & 4.2.2.10 & & \\
\hline PL3 & pectin (HG, RGI) & pectate lyase & 4.2.2.2 & 17 & 119,122 \\
\hline PL4 & pectin (RGI) & rhamnogalacturonan lyase & 4.2.2.- & 6 & 119,122 \\
\hline Total & & & & 44 & \\
\hline
\end{tabular}

Potential substrates, likely enzyme activity, EC number, the number of family members and references used to identify putative activities are shown. Proteins accession numbers and other characteristics are tabulated in Additional file 2 . HG = homogalacturonan, $\mathrm{RGI}=$ rhamnogalacturonan $\mathrm{I}$; GlcNAc = N-acetylglucosamine.

the GH12 family includes proteins with endo- $\beta-1,4$-glucanase, xyloglucanase, $\beta-1,3-1,4-$ glucanase and xyloglucan endotransglycosylase activity, sequence analysis suggests that the GH12 proteins from Phytophthora will hydrolyse $\beta$-1,4-glucan chains in cellulose or xyloglucans. Master and coworkers [82] have shown that $P$. sojae and $P$. ramorum $\mathrm{GH} 12$ proteins are closely related to a xyloglucan-specific endo- $\beta$-1,4-glucanase GH12 from Aspergillus. P. parasitica contains five proteins from the recently identified GH131 family. The few members of this family that been characterised have a number of enzyme activities and can act on $\beta-1,4-$ linked glucans as well as terminal $\beta-1,3-$ and $\beta-1,6-$ linked glucans [83].

\section{Auxiliary redox enzymes}

Recent research has led to the addition of the AA family of CAZymes to the original five GH, PL, CE, CBM and GT families within the CAZy database [21]. Currently there are 11 AA families listed in the CAZy database [43], some of which are polysaccharide oxygenases which are ostensibly involved in lignin breakdown but which also target cellulose in lignocellulose [21]. P. parasitica has 13 potentially secreted proteins from four AA families. Enzymes with AA8 modules are iron reductases, providing reactive oxygen species to assist in cellulose chain degradation [21]. Three $P$. parasitica proteins contain an AA8 module and share $42 \%$ identity (Table 2 and Additional file 2: Table S2). Although AA8 proteins

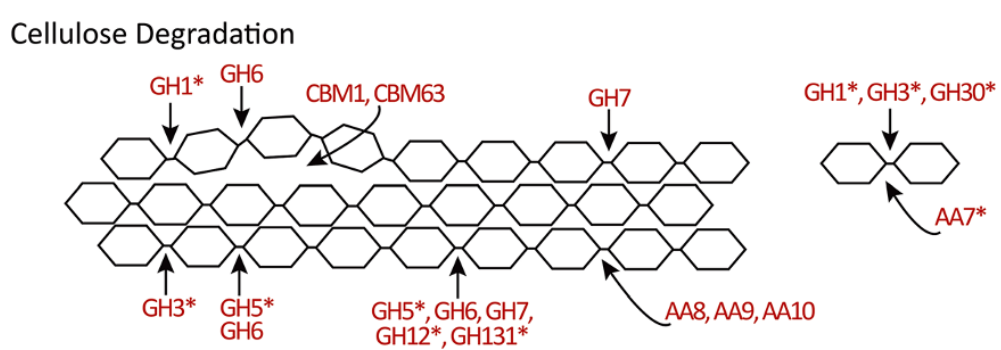

Figure 1 Diagrammatic representation of cellulose showing putative target sites for predicted $P$. parasitica CAZymes during cellulose degradation. The assigned enzymatic specificities are based on P. parasitica sequence homologies to characterised CWDEs. Asterisks indicate enzymes that are likely to act on more than one substrate. 

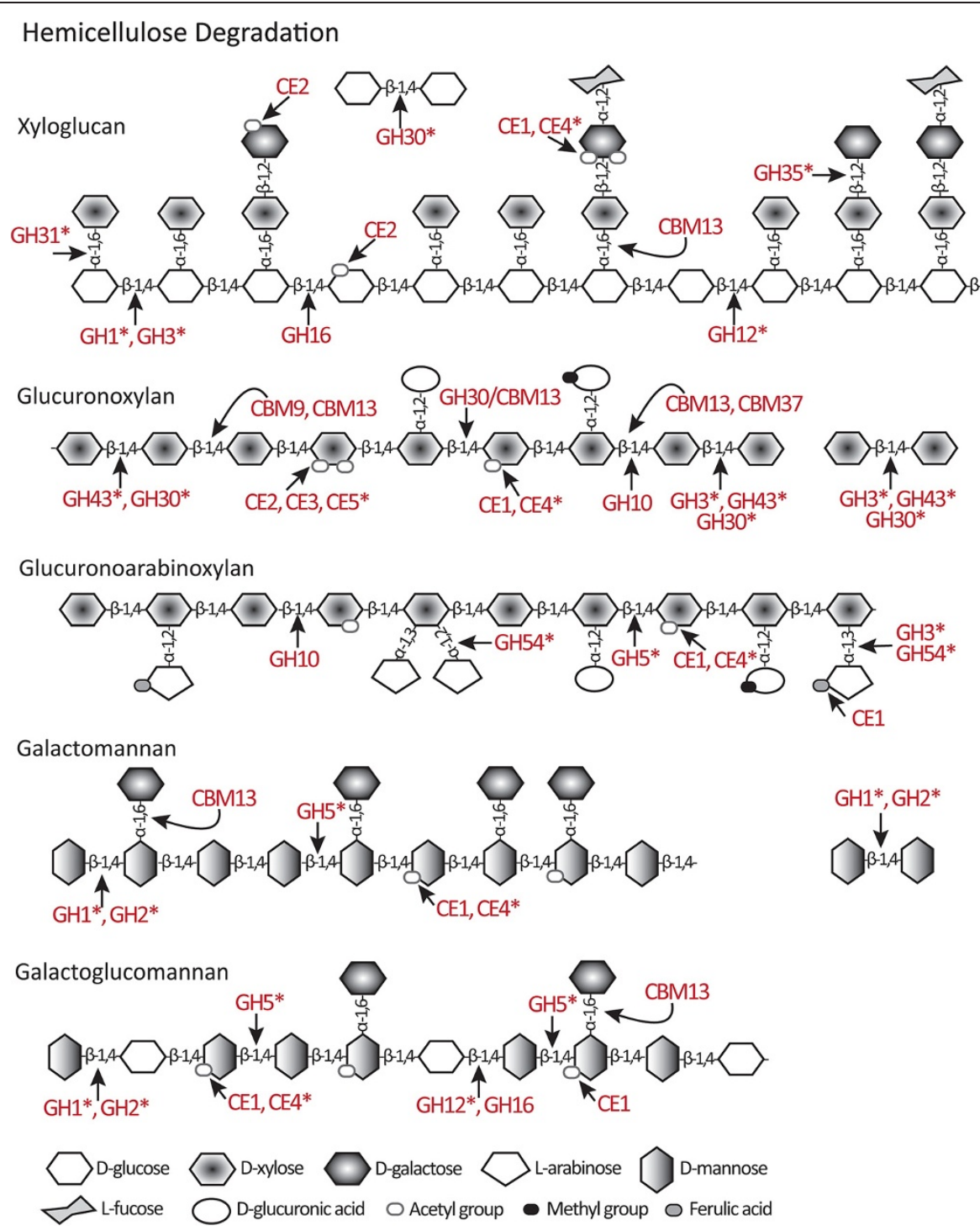

Figure 2 Diagrammatic representations of a range of hemicellulosic polysaccharides showing putative target sites for predicted $P$. parasitica CAZymes during hemicellulose degradation. The assigned enzymatic specificities are based on $P$. parasitica sequence homologies to characterised CWDEs. Asterisks indicate enzymes that are likely to act on more than one substrate.

typically also contain a C-terminal CBM1 module, thought to bring the enzyme and its reaction product close to the cellulose molecule [21], this motif did not occur in any P. parasitica AA8 proteins.

AA9 (formerly classified as GH61 proteins) and AA10 (formerly CBM33) families contain copper-dependent monooxygenases [84]. Both AA9 and AA10 enzymes directly target cellulose, oxidatively cleaving the glucose chains within the cellulose microfibrils $[21,85]$. AA9 enzymes are thought to oxidize the $\mathrm{C} 1, \mathrm{C} 4$ or $\mathrm{C} 6$ carbons in the glucose rings of the cellulose chains [86]. The action of AA9 and AA10 enzymes makes the cellulose more susceptible to attack by other CAZymes. AA9 proteins have been identified in a number of fungal genomes, with biotrophs containing only a few and hemibiotrophs and necrotrophs containing large AA9 families. C. higginsianum, for example, has 25 AA9 CAZymes [70]. To date, AA10 proteins have been predominantly found in bacteria and less commonly in eukaryotes [24]. The single AA9 and four AA10 copper-dependent monooxygenases in $P$. parasitica (Table 2 and Additional file 2: Table S2) have a high degree of similarity, sharing $42-61 \%$ pairwise identity. This sequence similarity suggests that the four genes may have arisen from a single progenitor gene through gene duplication. Examination of the $P$. parasitica scaffolds revealed that one AA10 and the sole AA9 gene are adjacent, a feature consistent with relatively recent gene duplication. $P$. parasitica also contains five secreted oxidases 
from the AA7 family. This family targets mono- and disaccharides and acts on a wide variety of substrates including cellobiose and $\alpha$-1,4-linked glycopyranosyl residues [87].

\section{Cellulose-associated CBMs}

CBMs are usually auxiliary domains that occur within proteins in conjunction with other CAZyme modules [78]. It is believed that the function of CBM modules is to bring the CAZyme into close and sustained proximity to the substrate of the catalytic CAZyme modules in the enzyme, thereby increasing the catalytic efficiency of the enzyme $[22,88]$. There are over 60 families of CBMs and they have been classified into three Types (A-C) according to the nature of their substrates (crystalline polysaccharides, soluble polysaccharides, or soluble mono-, di- or tri-saccharides, respectively) $[22,88]$.

The $P$. parasitica genome contains 29 genes encoding proteins that have CBMs that bind to cellulose (Table 2 and Additional file 2: Table S2). All contain signals for secretion with two containing GPI anchors (PPTG_04643 and 10047). Seventeen proteins belong to the CBM1 family and 12 to the CBM63 family. Both CBM1 and CBM63 are Type A CBM families that bind to crystalline cellulose $[22,88,89]$.

Of the 17 P. parasitica CBM1 proteins, eight were identified by dbCAN analysis (Additional file 1: Table S1) and the other nine by BLAST searches and confirmed as CBM1 proteins by CAT analysis (Additional file 2: Table S2). Pairwise comparisons show that they share little sequence similarity but most appear to contain at least one copy of a domain similar to previously identified fungal cellulose binding domains [90]. The cellulose-binding and lectin-like activity of one $P$. parasitica CBM1 protein has been demonstrated experimentally [PPTG_13482; CBEL, [90]]. CBEL is one of five proteins (the other four being PPTG_05833, 06045, 07987 and 19721) that have two CBM1 domains. Although only five CBM1 proteins have been recognised in the genome of $P$. infestans [30], the much larger number of CBM1 proteins in P. parasitica is similar to that found in hemibiotrophic and necrotrophic fungi $[30,70,71]$.

The 12 P. parasitica CBM63 proteins share $15-76 \%$ pairwise identity. They also contain amino acid signature sequences diagnostic of expansin-like proteins which function in the regulation of plant cell wall expansion [91]. Six of the CBM63 proteins [PPTG_18384, 18386, 18395, 18397, 19415 and 19485] also have a single TMD situated at the C-terminus and one [PPTG_19415] has two CBM63 domains. Unlike CBM1 proteins, the CBM63 family in $P$. parasitica is much larger than those found in biotrophic, hemibiotrophic and necrotrophic fungal pathogens $[70,71]$.
One of the interesting aspects of the cellulosetargeting CBM-containing proteins in $P$. parasitica is the fact that the CBM1 and CBM63 modules are not accompanied by catalytic modules. This is an unusual situation, only infrequently observed in CAZyme proteins $[22,78,92]$. Published reports on the CWDE complement of fungal plant pathogens have not focused on the modular structure of specific CAZyme proteins. However, an analysis of the $20 \mathrm{CBM} 1$-containing proteins in C. graminicola revealed only a single protein containing a CBM1 and no other module [93].

\section{Hemicellulose degrading families}

Hemicelluloses are complex heterogeneous polysaccharides defined by their solubility properties and include xyloglucans, xylans and mannans $[6,18]$. Xyloglucans are the most abundant form of hemicellulose in nongraminaceous plants. They have a backbone of $\beta-1,4-$ linked glucose subunits, up to $75 \%$ of which may be branched with an $\alpha-1,6$-xylose residue (Figure 2). The side branches may be further elaborated by $\beta-1,2$-galactose and $\alpha-1,2$-fucose substitutions. Xylans have a backbone of $\beta-1,4$-linked xylose subunits and can exist as simple unbranched chains or can contain many different side chains. In glucuronoxylans these branches are $\alpha$ 1,2-linked glucuronic acid subunits and in glucuronoarabinoxylans, the branches are arabinose or glucuronic acid subunits (Figure 2). Mannans possess a backbone of $\beta$-1,4-linked mannose residues and may include occasional glucose residues to form glucomannans. Backbone subunits may bear side chains of $\alpha-1,6$-linked galactose residues forming galactomannans and galactoglucomannans (Figure 2). Hemicelluloses are often acetylated and sometimes linked by esterification to feruloyl or coumaroyl residues [18]. Hemicelluloses are degraded by CAZymes that digest the xyloglucan, xylan or mannan backbones and that cleave the diversity of substitutions. Activity for the degradation of hemicellulose has been described in at least $33 \mathrm{GH}$ families and nine CE families [43]. In P. parasitica the degradation of hemicellulose potentially involves members of $12 \mathrm{GH}$ and five CE families as well as non-catalytic CBMs.

\section{Hemicellulose-targeting GHs}

Cleavage of the xyloglucan backbone is achieved by the action of $\beta$-1,4-endoglucanases and $\beta$-1,4-glucosidases which occur in a number of GH families (Figure 2). In P. parasitica, the GH1, GH3, GH12 and GH30 families include proteins that act on xyloglucan backbones $[18,66,68]$. Breakage of the $\beta-1,4$-linked glucans can also be achieved by xyloglucan-specific endo- $\beta$-1,4-glucanases from the diverse GH16 family [65]. The GH16 family members also act on $\beta$-1,3-galactans in AGPs, $\beta$ 1,3:1,4-glucans and $\beta-1,3$-glucans [94,95]. Of the $25 P$. 
parasitica proteins containing a GH16 module, 23 show a high degree of similarity and all but two [PPTG_09772 and 09773] contain the GH16 signature catalytic motif ExDxxE thought to be critical for xyloglucanase, galactanase and $\beta-1,3$-glucanase activity [65]; none contain the motif ExDxE found in GH16 $\beta-1,3-$ 1,4-glucanases $[95,96]$. Most proteins from this family contain two GH16 modules and are predicted to be secreted and/or contain a $\mathrm{C}$ terminal TMD (Additional file 2: Table S2). None of the $P$. parasitica GH16 proteins share significant homology to known endo- $\beta-1,3-$ galactanases [95]. The other two GH16 proteins lacking the ExDxxE motif [PPTG_03558 and 16550] show similarity to $\beta-1,3$-glucanases and are discussed in the section on $\beta$-1,3-glucan degradation.

The $\beta$-1,4-linked xylose residues in the backbone of xylans, glucuronoxylans and glucuronoarabinoxylans are generally cleaved by endo- $\beta-1,4-x y l a n a s e s$ found in GH5 and GH10, and by exo-acting $\beta-1,4$-xylanases $(\beta-1,4-$ xylosidases) from GH3, GH30, GH43 and GH54 families $[68,97]$. The $P$. parasitica genome encodes no xylanspecific GH5 proteins but does contain genes for four putative endo- $\beta-1,4$-xylanases from the GH10 family (Additional file 2: Table S2). Three of the four have an SP and share $45 \%$ amino acid identity, but the full sequence of the fourth protein could not be resolved (Additional file 1: Table S1, PPTG_17240). Other xylanases belong to one of the GH3 family subgroups, previously described in the section on cellulose-targeting hydrolases. This group contains four proteins [PPTG_05809, 14386, 14613 and 14623] sharing 31\% pairwise identity, and includes a protein annotated as a $\beta$-xylosidase [PPTG_14386]. This subgroup may thus be involved in the release of xylose residues from the end of xylans, glucuronoarabinoxylans and glucuronoxylans. Xylanases and xylosidases are also found in the GH43 family (Figure 2). In $P$. parasitica there are seven GH43 proteins and the six full-length proteins share between $56 \%$ and $88 \%$ pairwise identity [PPTG_15710, 15711, 15714, 15715, 17405 and $\left.17407^{\mathrm{CJO1A} 1}\right]$. However, these proteins share little homology to GH43 proteins involved in xyloglucan degradation [98]. Proteins in the GH43 family can also degrade $\alpha-1,3$ - and $\alpha$-1,5-linked arabinose-containing side chains (e.g. arabinogalactans) of hemicellulose, pectins and AGPs (Figures 2, 3, 4), and $\beta$-1,3-galactan linkages in AGPs (Figure 4). The P. parasitica GH43 proteins have considerable similarity to other uncharacterised GH43 arabinan endo- $\alpha-1,5$-arabinosidases such as those from A. niger and Myceliophthora thermophile [e.g. NCBI: XM_001393400, XM_003663619]. Interestingly the expression of one predicted GH43 [PPTG_17407] is induced by arabinogalactan suggesting that the closely related GH43s from $P$. parasitica may be involved in the degradation of side chains and not the xylan backbone of unsubstituted xylans (G Zhang, L Sofoulis, LM Blackman and AR Hardham, unpublished results). Xylosidases are also found in the GH54 family which is described in the pectinase section.

The GH30 family, in addition to the cellulose acting $\beta$ glucosidase/xylosidases described earlier, also contains proteins that can release xylose from glucuronoarabinoxylans and act on hemicellulose side chains such as $\beta$ 1,6 -glucanases and $\beta$-fucosidases, and endo- $\beta$ - 1,6 -galactanases and $\beta$-glucuronidases that degrade AGPs and pectins [43]. One $P$. parasitica group of GH30 contains five proteins [PPTG_08507, 08508, 08509, 08511 and 14259] with the four full-length proteins sharing an overall $50 \%$ amino acid identity. Members of this subfamily contain CBM13 domains (Additional file 2: Table 2), which have been shown in other organisms to associate with xylanases $[22,88]$. Another group of $P$. parasitica GH30s contains six proteins [PPTG_14859, 14860, 15283, 1601016065 and 18120], with five fulllength proteins having up to $44 \%$ identity with a secreted endo- $\beta$-1,6-galactanase from $C$. graminicola [NCBI: EFQ35891]. This sequence similarity suggests that members of this subfamily of $P$. parasitica GH30 proteins, like their fungal counterparts [99], may act on arabinose- and galactose-containing side chains (arabinogalactans) found in pectins (Figure 3) and AGPs (Figure 4).

Putative $P$. parasitica enzymes with predicted activity against mannan-based hemicelluloses are found in the GH1, GH2 and GH5 families. Two proteins from the $P$. parasitica GH5 family have been annotated as endo- $\beta$ 1,4-mannosidases [PPTG_03499 and 18368] and these share more similarity to characterised mannosidases [e.g. NCBI: AAS19695 from the bacteria Cellvibrio mixtus] than to other $P$. parasitica GH5s. A single GH2 protein containing an SP [PPTG_12094] was identified and this protein had more residues in common with a $\beta$ mannosidase from A. nidulans [NCBI: ABF50864] than to a $\beta$-galactosidase from Xanthomonas campestris pv. campestris [NCBI: AAP86765]. $\beta$-galactosidases that have the potential to act at the terminal non-reducing end xyloglucan side chains can also be found in GH1, GH3 and GH35, and are described later. It is possible that the $P$. parasitica GH2 may also be involved in the degradation of $N$-linked oligosaccharides (Figure 4 ) by cleaving the $\beta-1,4$ linkage between mannose and $\mathrm{N}$-acetylglucosamine [64].

\section{Hemicellulose-targeting CEs}

The formation of cross-links between hemicelluloses and cellulose is moderated by the presence of acetyl, methyl and phenolic groups on backbone and side chain residues in the hemicellulose molecule [3]. Galactose residues in the backbones of xylans, glucuronoarabinoxylans and glucuronoxylans, and in the side chains of 


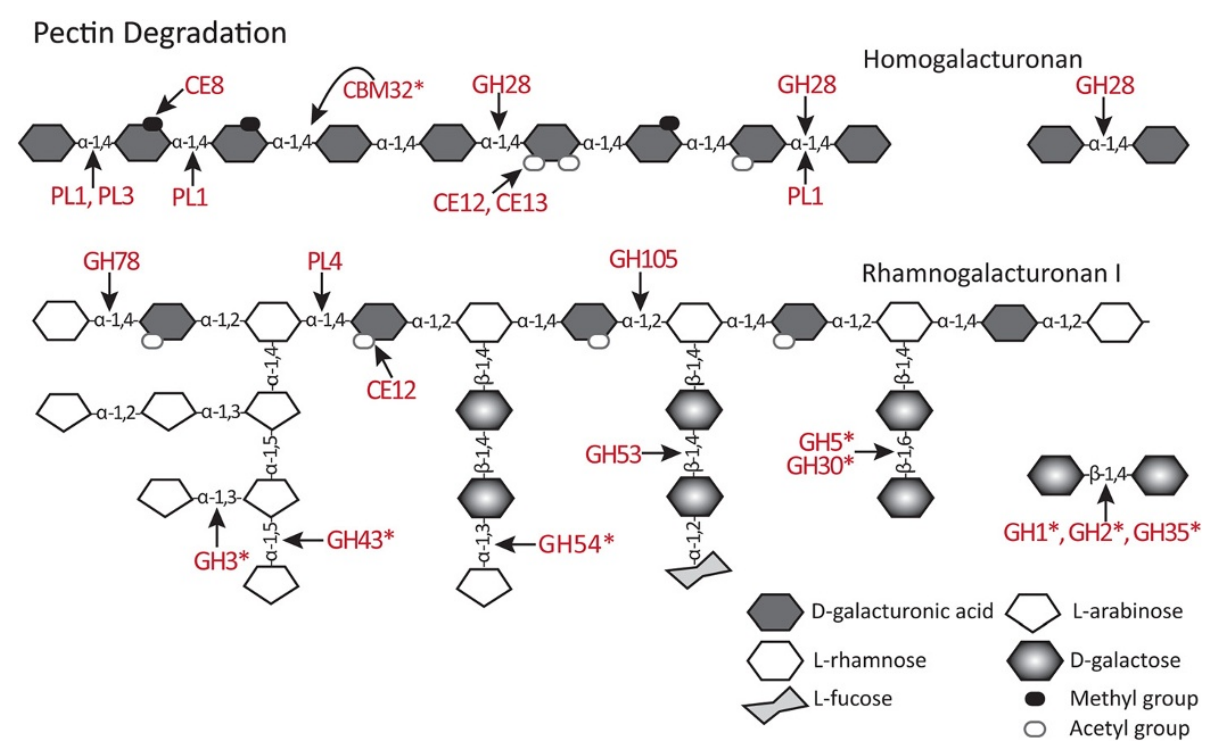

Figure 3 Diagrammatic representation of two pectic polysaccharides showing putative target sites for predicted $P$. parasitica CAZymes during pectin degradation. The assigned enzymatic specificities are based on $P$. parasitica sequence homologies to characterised CWDEs Asterisks indicate enzymes that are likely to act on more than one substrate.

xyloglucans, galactomannans and galactoglucomannans can be acetylated and glucuronic acid residues can be methylated. Ferulic acid and coumaric acid can be attached to arabinose residues in side chains in glucuronoxylans and glucuronoarabinoxylans (Figure 2). These modifications can be removed by CEs [100]. There are currently eight known $\mathrm{CE}$ families with acetyl xylan esterase activity (families CE1-7 and CE16) and the P. parasitica genome contains members of five of these $\mathrm{CE}$ families (Table 3).

The CE1 family includes acetyl xylan esterase and feruloyl esterase, as well as intracellular esterases, such as S-formylglutathione hydrolase [43]. In P. parasitica, 34 putative CE1 proteins were identified by dbCAN with Evalues between $1.4 \mathrm{e}-4$ and $7.10 \mathrm{e}-48$ (Additional file 1 : Table S1) and another four were found by homology searches of the $P$. parasitica genome. However, none of the 38 proteins had domains or lengths consistent with CE1 proteins as indicated by CAT analysis. Currently, 96\% of the 3,042 CE1 proteins listed in the CAZy database [43] are from bacteria, indicating that eukaryotes contain few CE1 proteins. Three P. parasitica proteins, sharing 37\% identity, contain the Pfam domain PF07519 for tannase and feruloyl esterase [PPTG_00806, 06868 and $19565^{\mathrm{P1569}}$ ], but only one of these was identified as a CE1 protein by dbCAN [PPTG_06868]. These three proteins share $20-22 \%$ amino acid residues with a characterized feruloyl esterase from A. niger [NCBI: CAC83933, [101]]. Interestingly, of the eight proteins annotated as tannase and feruloyl esterases in C. graminicola, only one has a CE1 domain [93].
A small number of putative acetyl xylan esterases from CE2, CE3, CE4 and CE5 families were identified in the $P$. parasitica genome. CE2 proteins have a preference for acetyl groups on the carbon at the C6-position of the xylose ring while CE3 esterases remove acetyl groups from a number of carbons [100]. Single acetyl xylan esterases were identified from the CE2 and CE3 families in $P$. parasitica. Fungal pathogens studied to date tend to have small CE2 families but large CE3 families [70,71]. The $P$. parasitica CE2 protein did not have a classical or a non-classical SP but did have $40 \%$ identity with a putative CE2 from Albugo laibachii [NCBI: CCA14218] and $20 \%$ identity with a characterised CE2 from Neocallimastix patriciarum [NCBI: AAB69091 partial protein, [102]]. Homologs to the single potentially secreted $P$. parasitica CE3 protein were identified in EST libraries of mating cultures of $P$. infestans [NCBI: CV939145, [103]] and mycelia of P. capsici [NCBI: FG042841 and FG042841]. Genes encoding two potentially secreted CE4 proteins were found in the $P$. parasitica genome [PPTG_01441 and 12926] but both had little homology to characterised CE4 proteins [104]. PPTG_12926 contained an N-terminal TMD but PPTG_01441 did not, suggesting that these enzymes serve different functions. CE4 proteins have broad specificity (Figures 2 and 4), acting on acetylated residues in xyloglucans and xylans and on $\mathrm{N}$-acetylglucosamine in chitin and $\mathrm{N}$-linked oligosaccharides $[105,106]$.

P. parasitica contains four CE5 proteins. CE5 acetyl xylan esterases act predominantly on acetyl groups on the $\mathrm{C} 2$-position of xylose residues such as those in 


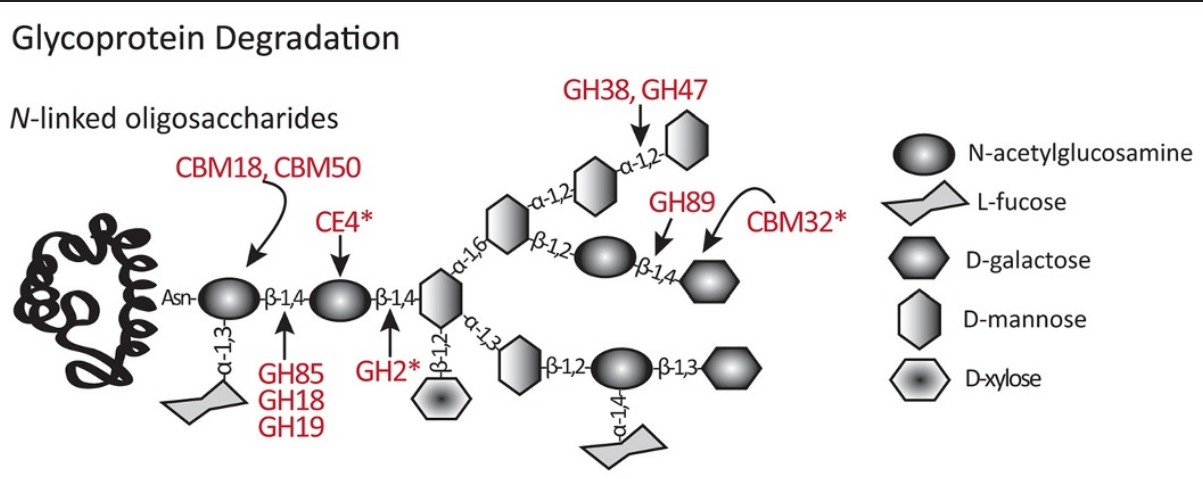

O-linked oligosaccharides
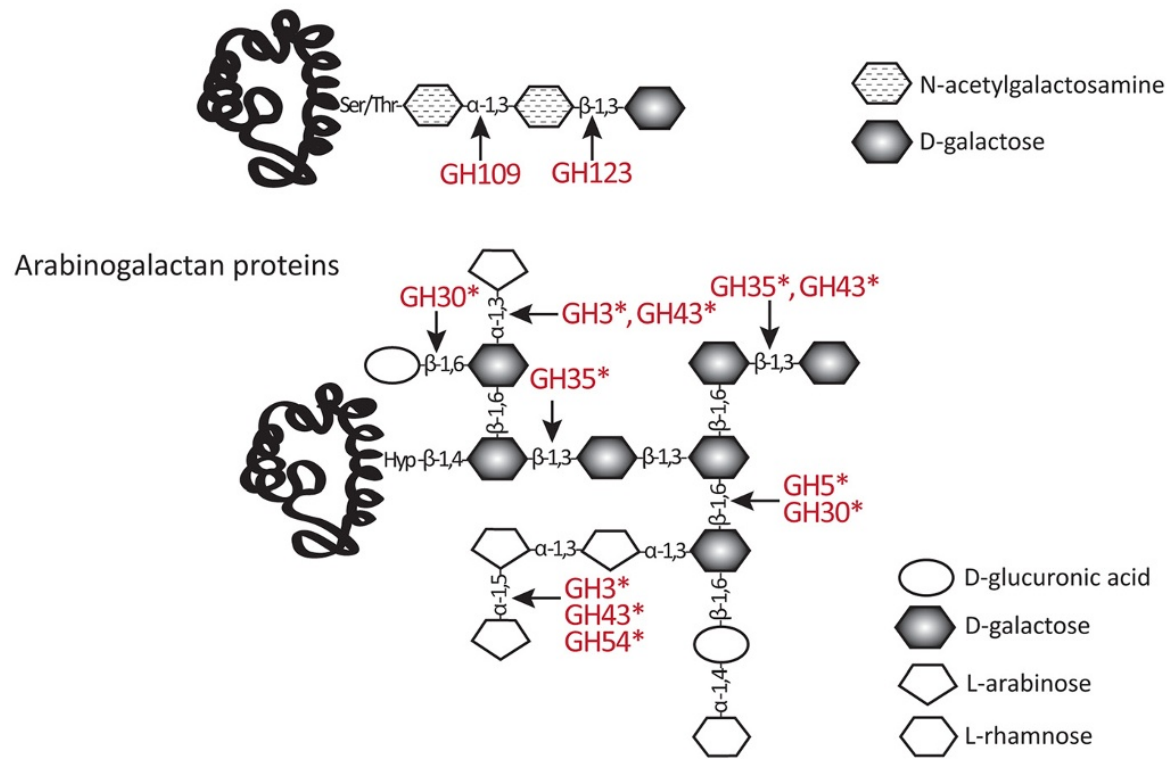

Figure 4 Diagrammatic representation of three different types of glycoproteins showing putative target sites for predicted $P$. parasitica CAZymes during their degradation. The assigned enzymatic specificities are based on P. parasitica sequence homologies to characterised CWDEs. Asterisks indicate enzymes that are likely to act on more than one substrate.

glucuronoxylans (Figure 2) [100,107]. After using EST data to correct an apparent annotation error for one of these genes [PPTG_19214], all four P. parasitica CE5 proteins are predicted to be secreted. Three proteins [PPTG_07182, 19214 and 19215] shared 60\% amino acid identity and had homology to characterised acetyl xylan esterases [NCBI: ADZ98863, [107] and cutinases [NCBI: AAA33334, [108]. However, despite the homology to cutinases, none of these three proteins contains the cutinase consensus sequence [G-H/Y-S-X-G, [109]. On the other hand, the fourth $P$. parasitica CE5 [PPTG_08907] protein, which is annotated as a lipase, does contain the cutinase consensus sequence. Two predicted CE7 proteins [PPTG_03864 and 08082] with $\mathrm{dbCAN}$ values of $6.80 \mathrm{e}-05$ and $9.80 \mathrm{e}-12$ were identified (Additional file 1: Table S1). Given that all characterized CE7 enzymes function in the cytoplasm, it seems unlikely that these two $P$. parasitica proteins are involved in the degradation of cell wall components [100].

\section{Hemicellulose-targeting CBMs}

Three families of CBMs with putative hemicellulose binding properties, CBM9, CBM13 and CBM37, were identified in P. parasitica (Table 2). In other organisms, CBM9 modules often accompany modules conveying endo- $\beta$-1,4-xylanase activity [92] but the one $P$. parasitica CBM9 protein lacks this or any other CAZyme module. CBM13 modules often occur in multi-domain proteins that preferentially target $\beta$-1,4-linked xylans but can bind to other polysaccharides [22,88]. Four of the 10 P. parasitica proteins containing CBM13 modules also contain a GH30 module and are annotated as glycosphingolipid acting glucosylceramidases [PPTG_08507, 08508, 08509 and 08511]. The presence of the CBM13 modules may indicate a role for these proteins in the 
degradation of xylans rather than of glycosphingolipids. Three proteins $\left[\right.$ PPTG_ $09700^{\mathrm{P} 10297}, 09701^{\mathrm{P} 1569}$, and 18983] contain a CBM13 and a GH17 module, suggesting that these may act on $\beta$-1,3-glucans. The other four CBM13 proteins contain from one [PPTG_16933], three [PPTG_09699 and 20351] to six [PPTG_15107] copies of the CBM13 module. One P. parasitica protein containing a CBM37 domain was identified [PPTG_01092]. CBM37 domains have been shown to bind to a number of substrates including xylan and cellulose [78]. However PPTG_01092 is predicted to have a molecular weight of over $600 \mathrm{kDa}$ and contains other domains not found in CWDEs. This protein was thus not analysed further.

\section{Pectin degrading families}

The pectin matrix of plant cell walls is constructed using three main highly complex polysaccharides, HG, RGI and RGII [9]. HG consists of unsubstituted chains of $\alpha-$ 1,4-linked-galacturonic acid residues (Figure 3). RGI has a backbone of alternating $\alpha-1,2$-rhamnosyl and $\alpha-1,4-$ galacturonic acid residues with different side chains substituted onto the rhamnose residues (Figure 3). The side chains include $\alpha$-1,5-linked arabinans, which are in turn substituted with $\alpha-1,3$-arabinans, and arabinogalactans, which consist of $\beta$-1,4-galactose substituted with $\alpha-1,3$-arabinans [9]. Residues in HG and RGI can be methyl esterified or acetylated [4]. The highly complex RGIIs are dimers of seven to nine $\alpha$-1,4-linked galacturonic acid residues. These backbones are highly substituted with oligosaccharides that include 20 different linkages and 12 different saccharides, forming a complex polysaccharide that is highly resistant to degradation [110]. The CAZy database includes 28 CAZyme families (18 GHs, three CEs and seven PLs) involved in the degradation of pectins. The $P$. parasitica genome includes genes in 18 of these families (12 GHs, three CEs and three PLs).

\section{Pectin-targeting GHs}

The HG chain of $\alpha-1,4$-linked galacturonic acid residues is cleaved by $\mathrm{GH} 28$ endo-polygalacturonases. The GH28 family also contains exo-polygalacturonosidases and enzymes acting on the backbone of $\alpha-1,2$ linked galacturonic acid and rhamnose residues in RGI. The $P$. parasitica genome contains 18 genes encoding secreted proteins from the GH28 family. All 18 proteins share a high degree of similarity, especially in the C-terminal half. Alignment of 16 fulllength GH28 proteins showed they share 30\% identity. Functional studies of eight $P$. parasitica GH28 proteins have demonstrated that they are endo-polygalacturonases $[111,112]$. In $A$. niger, the sequences of the endopolygalacturonases are very different from those of exopolygalacturonosidases and rhamnogalacturonases [NCBI: ABD61567, ABD61568, CAK41025, A2QK83, ABD61564 and CAA41693] suggesting that the 18 P. parasitica GH28 proteins all have endo-polygalacturonase activity.

In $P$. parasitica, proteins in two other $\mathrm{GH}$ families are likely to be involved in the degradation of the RGI backbone, namely GH78 and GH105. GH78 enzymes specifically cleave the terminal non-reducing end $\alpha-1,2$-rhamnose [113] while GH105 proteins are endo-acting enzymes that cleave the $\alpha-1,2$ bond between the galacturonan and rhamnose residues [114]. $P$. parasitica has four putative GH78 enzymes, three of which are very similar (68\% identity; PPTG_00925, 00925 and $00922^{\mathrm{P} 1269}$ ), and one GH105.

Nine GH families, GH1, GH2, GH3, GH5, GH30, GH35, GH43, GH53 and GH54, include proteins that have the potential to degrade RGI side chains. Rhamnose residues in the RGI backbone are substituted with side chains of $\beta$-1,4-linked galactan, $\alpha-1,3-$ and $\alpha-1,5$-linked arabinan or branched type I arabinogalactans with small amounts of fucosyl, glucosyluronic acid and methyl $\beta$ glucosyluronic acid [4]. Potentially, the GH1, GH2, GH5 and GH30 families, described earlier, and GH35 (in which $P$. parasitica has one secreted protein), contain $\beta$ galactosidases that act on the terminal non-reducing end $\beta$-1,4-linked galactose residues in xyloglucan (Figure 2) and RGI side chains (Figure 3 ) and some also act on the $\beta-1,3-$ and $\beta$-1,6-linked galactans of AGPs (Figure 4) $[64,115]$. Unfortunately, sequence analysis has not helped determine the substrate specificity of the $P$. parasitica proteins in these five families.

$P$. parasitica has proteins in four CAZyme families, GH3, GH43, GH53 and GH54, that include enzymes that target $\alpha$-1,3- and $\alpha$-1,5-linked arabinan or branched type I arabinogalactans. GH3 and GH43 have been described earlier. GH53 enzymes specifically cleave the $\beta$ 1,4-linked galactose residues in the arabinogalactan type I side chain of RGI. There are six P. parasitica GH53 proteins, of which two predicted proteins [PPTG_19165 and 19166] may be misannotated because scaffold analysis suggests that they form a single protein. The four full-length proteins share $46 \%$ amino acid identity and contain two catalytic residues typically found in endo- $\beta$ 1,4-galactosidases [116]. Enzymes in the GH54 family with $\alpha$-L-arabinofuranosidase activity cleave the terminal $\alpha-1,3-$ or $\alpha-1,5$ - linked arabinose residues in glucuronoarabinoxylans (Figure 2) and in arabinogalactan side chains of RGI (Figure 3) and AGPs (Figure 4). There is a single secreted GH54 in $P$. parasitica and it differs from fungal GH54 proteins in that it does not contain a xylan specific CBM42 module $[117,118]$. This suggests that the $P$. parasitica GH54 protein, while sharing significant homology to the GH54 module from fungi [e.g. NCBI: BAG80559 from Fusarium oxysporum and NCBI: XP_003711856 from Magnaporthe oryzae], does not act on hemicellulose. 
While an accurate estimation of the number of $\mathrm{GH}$ proteins involved in pectin degradation is difficult, analysis of fungal and Oomycete genomes suggests that hemibiotrophs and necrotrophs contain more pectindegrading enzymes than biotrophs [31,69-71]. However, the CAZyme families from which the pectin degrading $\mathrm{GH}$ proteins come differ between fungi and Oomycetes. Fungal pectinases occur in the GH51 and GH62 families but these two CAZyme families are not represented in the Oomycetes. Both fungi and $P$. parasitica have pectinases in GH1, GH2, GH30, GH43 and GH53 families but proteins in GH1, GH30 and GH53 families are more abundant in Oomycetes than in fungi whereas proteins in GH2 and GH43 families are more abundant in fungi. Bacteria also have GH4, GH42, GH50 and GH59 pectinases but these families are not represented in fungi or Oomycetes [43].

\section{Polysaccharide lyases}

CAZyme activities that degrade pectins via $\beta$-elimination are grouped in 22 PL families [119]. The P. parasitica genome contains 44 PLs and these occur in the PL1, PL3 and PL4 families (Table 3). All are predicted to be secreted and none contain TMDs. Both PL1 and PL3 families contain pectate lyases that cleave bonds linking the $\alpha$-1,4-galacturonan residues to the $\mathrm{HG}$ backbone at the non-reducing end. PL1 also contains enzymes that target unesterified $\alpha$ 1,4-galacturonan residues at the reducing end (exo-pectate lyase) and esterified $\alpha-1,4$-galacturonan residues at the non-reducing end (pectin lyase) of HG. PL4 proteins act on the RGI backbone, breaking the $\alpha-1,4$ glycosidic bonds between the alternating L-rhamnose and D-galacturonic acid residues. Alignment of $P$. parasitica full-length PL1 proteins showed that they have a number of conserved residues, with pairwise identity ranging from $21 \%$ to $100 \%$. Two PL1 proteins from P. capsici, Pcpel1 and Pcpel2 [NCBI: FJ213434, FJ213435] have been identified as pectate lyases, having activity against unesterified polygalacturonic acid (PGA) [120,121]. Pcpel2 has 74-90\% amino acid identity with three $P$. parasitica PL1s [PPTG_12901, 12902 and 20388] while Pcpel1 has $87 \%$ identity with one $P$. parasitica PL1 [PPTG_18908], suggesting that these P. parasitica proteins will act on unesterified HG. The $P$. parasitica genome contains 17 putative PL3 proteins that show a high degree of homology in their $\mathrm{N}$ terminal half. There are six predicted $P$. parasitica PL4 proteins but misannotation may be splitting one protein into two [PPTG_05070 and 05071]. The four that are full-length share 51-83\% amino acid identity and contain the highly conserved regions thought to be responsible for binding to deacetylated RGI [122].

Although the number of CAZyme families that contain PL enzymes is similar in the Oomycete and fungal phytopathogens that have been examined, the numbers of PL proteins in P. parasitica and other Phytophthora species is more than twice that in necrotropic Pythium species [31] and considerably larger than in fungi [69-71]. A similar situation is seen in the pectin degrading CE families.

\section{Pectin-targeting CEs}

The three $P$. parasitica CE families that are not involved in hemicellulose degradation contain enzymes that are predicted to remove the methyl and acetyl groups from pectins (Table 3). The single activity of CE8 proteins is to remove methyl groups from the $\alpha$-1,4-galacturonic acid residues in HG [18]. CE12 proteins remove the acetyl group from galacturonic acid residues in HG and RGI, and CE13 proteins remove the acetyl group from HG only (Figure 3). P. parasitica has 15 proteins in the CE8 family (Additional file 2: Table S2). Alignments of these proteins showed that they have $28 \%$ amino acid identity overall and 54-100\% identity in pairwise comparisons. $P$. infestans and P. sojae have 11 and 19 CE8 proteins, respectively. By contrast, Pythium species examined to date have no CE8 proteins [31]. Deesterification by CE8 proteins is thought to be essential for subsequent degradation of $\mathrm{HG}$ by $\mathrm{GH} 28$ proteins [123].

There are 14 CE12 and six CE13 proteins in $P$. parasitica, making these families larger in $P$. parasitica than in fungal plant pathogens. Only a few fungal phytopathogens contain any CE13 proteins although they do occur in plants [69-71,124]. The sequence of the $14 \mathrm{P}$. parasitica CE12 proteins is highly variable (only $8 \%$ amino acid identity) but all contain RGI acetyl esterase signature amino acid residues [125]. Sequence analysis revealed 18-74\% pairwise amino acid identity, and an N-terminal TMD in another five proteins, and all are predicted to be secreted. Together, these data suggest there may be some functional differences within the $P$. parasitica CE12 family. The six CE13 proteins contain classical secretion signals and share between 38-68\% amino acid identity in pairwise alignments. One CE13 protein [PPTG_19428] contains a predicted GPI anchor so it may have a different function to that of the other five CE13 enzymes.

\section{Pectin-targeting CBMs}

One protein containing CBM32 was identified in $P$. parasitica. CBM32 modules can interact with PGA and can be associated with $N$-acetylglucosaminidase modules [126]. CBM32 modules are found in many fungal species but, as in $P$. parasitica, are present in relatively low numbers of proteins.

\section{$\beta$-1,3-glucan degradation}

$P$. parasitica contains three $\mathrm{GH}$ families, GH16, GH17 and GH81, that include proteins with predicted endo- $\beta$ - 
1,3-glucanase activity. Of the 25 proteins in the GH16 family, 23 are predicted to act on hemicellulose or $\beta-1,3-$ glucans (described earlier). Of the two remaining GH16 proteins, PPTG_16550 has homology to TOS1-like proteins [e. g. NCBI: EMR65012 from Eutypa lata and NCBI: EJT42179 from Saccharomyces kudriavzevii]. TOS1 proteins have some similarity to known $\beta$-1,3-glucanases and mutation of the TOS1 gene from S. cerevisiae results in altered glycogen levels and wall modification [96]. The other GH16 protein [PPTG_03558] has a dbCAN value of 1.7e-05 and has some homology to PPTG_16550 and to non-CAZyme carboxypeptidases. There are 20 proteins in the GH17 family in P. parasitica, three of which [PPTG_18983, 09700 ${ }^{\mathrm{P} 10297}$ and $09701^{\mathrm{P} 1569}$ ] also contain a CBM13 module. All but one of the full-length proteins are predicted to be secreted with two also containing a TMD at the C-terminus (Additional file 2: Table S2). The GH17 proteins lack the ExDxxE and EESTSED signature sequences found in GH16 and GH81 $\beta$-1,3-glucanases $[127,128]$. All full-length proteins, while sharing little overall similarity, could be divided into subgroups and a NCBI BLASTp analysis showed that all contained a COG5309 domain found in exo- $\beta-1,3$-glucanases [39]. The GH81 family contains 16 proteins identified as endo- $\beta-1,3$-glucanases. An alignment of the GH81 proteins [including PPTG_13594 ${ }^{\text {P10297, }}$ $19888^{\mathrm{P} 10297}$ and $19889^{\mathrm{P} 10297}$ ] showed high sequence conservation in some regions and the presence of the EESTSED endo- $\beta$-1,3-glucanase signature motif [127]. GH17 and GH81 but not GH16 families are considerably larger in Phytophthora species than in other phytopathogens $[31,70,71]$, a feature that may indicate a role other than degradation of the plant cell wall. These enzymes could, for example, be involved in the modification of $\beta$ 1,3-glucans in Phytophthora walls [77,129].

A fourth CAZyme family whose members may be involved in remodeling $\beta$-1,3-glucans via hydrolase and transferase activity is GH72 $[69,130,131]$. P parasitica has 14 GH72 proteins, a number at least twice that in fungal species examined to date [70,71]. The overall similarity between $P$. parasitica GH72 proteins is low, although five proteins share $24 \%$ amino acid identity and contain a GPI anchor, a feature typically seen in GH72 proteins from other organisms [131].

\section{Putative chitinases}

Chitin is a polymer of $\mathrm{N}$-acetyl-glucosamine residues and constitutes the main microfibrillar component of fungal cell walls and the exoskeletons of arthropods and insects. Chitinases act on the $N$-acetyl- $\beta$-1,4-glucosaminide linkage in both chitin and glycoproteins [64,132]. P. parasitica contains proteins from two $\mathrm{GH}$ families that include members with chitinase activity. Three proteins belong to the GH18 family, members of which have chitinase or endo- $N$-acetyl- $\beta$-1,4-glucosaminidase activity, or even inhibit xylanase activity [132]. The two full-length $P$. parasitica GH18 proteins share only $12 \%$ amino acid identity and show similarity to mammalian, but not to plant chitinases. However, all three proteins contain regions with homology to the GH10 and GH11 binding sites in xylanase inhibitors such as XIP-1 from Triticum aestivum [NCBI: CAD19479]. The function of these GH18 proteins is thus unclear. GH19 family proteins characterised to date have chitinase, $\beta$ - $N$-acetylglucosaminidase or lysozyme activity [64]. The two $P$. parasitica GH19 proteins are almost identical, and have sequence homology with plant chitinases. They have, for example, 27-29\% pairwise amino acid identity to a chitinase from Medicago sativa [NCBI: ABX90065].

The $P$. parasitica genome also encodes proteins with two CBM modules (CBM18 and CBM50) that confer chitin binding $[133,134]$. One $P$. parasitica protein has two CBM18 modules and an SP. In other organisms, CBM18 modules often accompany GH18 modules in chitinases [133] but this was not the case in P. parasitica. Three proteins had either one [PPTG_05472] or three [PPTG_09231 and 09232] CBM50 modules and two are predicted to be secreted by the non-classical pathway (Additional file 2: Table S2). PPTG_05472 was considerably larger than the other two CBM50 proteins and also contained two fibronectin type III domains, which are associated with mammalian extracellular proteins, and a LysM motif, which is known to bind peptidoglycans and chitin [135]. Homologs of this CBM50 protein are restricted to the Stramenopiles.

\section{Degradation of other $\mathrm{N}$-acetylated polysaccharides and glycoproteins}

The $P$. parasitica genome encodes proteins from $12 \mathrm{GH}$ families that include enzymes involved in cleavage of non-chitinaceous $\mathrm{N}$-acetylated polysaccharides and glycoproteins, some of which have been described in other sections (Figure 4). There is one representative in the GH38 family of putative glycoprotein-acting $\alpha$-mannosidases [136]. There are five GH47 proteins, four of which are predicted to be secreted (Additional file 2: Table S2). GH47 proteins are associated with modification or degradation of glycoproteins containing $\alpha$-1,2-linked mannose residues [136]. Two of the P. parasitica GH47 proteins have 33\% identity [PPTG_01016 and 16418] but the other three are disimilar. One protein belonging to the GH63 family of $\alpha$-glucosidases is predicted to be secreted, contained an N-terminal TMD and the three catalytic residues typical of $\alpha$-glucosidases involved in $\mathrm{N}$-glycan processing [137].

Proteins in the GH85 family are predicted to have endo- $\beta-N$-acetylglucosaminidase activity, to act on Asnlinked glycopeptides and to cleave between mannose 
and $N$-acetylglucosamine [138]. $P$. parasitica contains one GH85 protein which lacks an SP and two exo- $\alpha-D-N$-acetylglucosaminidases with an SP in the GH89 family. In Clostridium perfringens, proteins from this relatively uncharacterised family act on $\alpha-N$-acetylglucosamine- $\beta$ 1,4-D-galactose residues [139]. In plants, these residues are found in inositol-glycosphingolipids [140]. Seven $P$. parasitica proteins with conserved domains typical of oxidoreductase (Pfam01408 and Pfam02894) grouped within the GH109 family which is associated with $\alpha-N$-acetylgalactosaminidase activity [43]. One $P$. parasitica protein [PPTG_03206] had a GH123 module associated with glycosphingolipid $\beta$ - $N$-acetylgalactosaminidase activity and thought to act on terminal $\alpha$-linked $N$-acetylgalactosamine units from $O$-glycoproteins. The $P$. parasitica $\mathrm{GH} 123$ protein lacked an SP but contained a motif whose score was only slightly below the threshold for non-classical secretion as determined by SecrotomeP.

\section{Degradation of starch}

Starch molecules contain $\alpha$-1,4-linked glucans with $\alpha$ 1,6 branch points. The $\alpha-1,4$-linked glucan chains are cleaved by endo-acting amylase or by $\alpha$-glucosidase acting on the terminal, non-reducing end to release Dglucose. $P$. parasitica contains proteins in five CAZyme families with modules associated with the degradation of starch. The families are GH13 [141], GH31 [18], CBM20 [142], CBM25 [92] and CBM47 [78]. These families have been included in the current study because most contain proteins that are predicted to be secreted (Additional file 2: Table S2) and may act on substrates other than starch. For example, $\alpha$-mannosidases from the GH31 family could be involved maturation of glycoproteins [143].

Two $P$. parasitica GH13 proteins were identified. One contains the $\alpha$-amylase catalytic domain, an SP and an Nterminal starch-binding CBM25 domain. A CBM25 domain was also found in one of the ten GH31 P. parasitica proteins [PPTG_01216]. The GH31 proteins could be divided into five subfamilies based on sequence homologies. Excluding two potentially truncated proteins, one group of three share 68\% amino acid identity [PPTG_01216, $01217^{\text {CJ01A1 }}$ and 09366 ${ }^{\text {CJ01A1 }}$ ], PPTG_03687 and 10577 share $70 \%$ identity, another two have $87 \%$ amino acid identity [PPTG_02261 and 07818] and one protein shared only limited homology [PPTG_12379]. Nine of the GH31 proteins are predicted to be secreted and one of these [PPTG_12379] has a predicted TMD at the Cterminus. All proteins aligned with different groups of $\alpha$-glucosidases identified by BLASTp searches of NCBI, indicating they probably act in the degradation of starch. However they all shared some residues (12-18\%) with a characterised $\alpha$-xylosidase from Cellvibrio japonicus [144], leaving open the possibility that some of the $P$. parasitica GH31 family may act on terminal $\alpha$ linked xylose residues of xyloglucans (Figure 2).

The final protein which may be involved in starch degradation contains both a CBM20 and a fucose-binding CBM47 module [PPTG_20189]. This is a CAZyme module combination that has not been previously described in any other organism. Initially, five CBM20/CBM47 proteins were identified by the dbCAN analysis with Evalues between $7.50 \mathrm{e}-05$ and $6.50 \mathrm{e}-19$. However, BLAST analysis showed that two of the five have more homology to regulator-chromosome condensation proteins than to known CAZymes. The remaining three proteins [PPTG_02680, 08934 and 18605], contain other domains not associated with CAZymes. PPTG_08934, for example, contains a discoidin domain found in an adhesion protein from Dictyostelium discoideum [145].

\section{Other possible CWDEs}

The $P$. parasitica genome contains six proteins in the GH32 family which includes enzymes with invertase, exoinulinase, levanase and fructan exohydrolase activity [146]. The $P$. parasitica GH32 proteins were almost identical to $P$. infestans invertases characterised by Judelson and coworkers [147]. Two P. parasitica $\alpha, \alpha$-trehalases in the GH37 family both contain an SP, suggesting that they act on an extracellular source of trehalose ( $\alpha$-D-glucopyranosyl- $\alpha$-D-glucopyranoside) to release glucose.

Two proteins containing CBM38 or CBM57 modules were identified. Few fungi contain CBM38 proteins and both CBM38 and CBM57 modules are poorly characterised [43]. Two P. parasitica proteins had CBM40 modules. CBM40 proteins have been found in a few fungi, but in bacteria this module has been found in sialidases [78].

\section{Comparison of the complement of CWDEs in $P$. parasitica with that in $P$. infestans}

As a comparative exercise, we have applied our bioinformatic strategy for the identification of CWDEs to the $P$. infestans genome [148]. A summary of the numbers of carbohydrate-active proteins identified in $P$. parasitica and $P$. infestans in the current study is presented in Table 4. CAZyme families and CAZyme modules were initially identified using dbCAN, BLAST, keyword and domain searches (Additional files 3 and 4). Subsequent detailed bioinformatic analysis of individual proteins revealed that some CAZymes were cytoplasmic proteins or had alternative enzyme activities and were thus not CWDEs. Removal of these proteins from the pool of candidate CWDEs meant that the number of CWDE families is less than the number of CAZyme families in each class of enzymes. Our data show that the numbers of CWDE families and CWDE proteins in each CAZyme class are remarkably similar in $P$. parasitica and $P$. 
infestans. Comparison of our data with those from three other recent $P$. infestans studies [29-31,149,150] exemplifies the variation in CAZyme annotation achieved following different approaches. The time at which the analysis is done is also an important factor. For example, the AA class of CAZymes has only relatively recently been included within the CAZy database [21] and this explains the absence of data for AA families in the earlier $P$. infestans studies. The time at which the analysis is conducted also affects the results because of continuing changes in the annotation of the genome sequence data. In terms of the numbers of CBM, CE, GH, GT and PL CAZyme families, the numbers in the four studies are quite similar.

\section{Conclusions}

Searches of the $P$. parasitica genome using dbCAN and BLAST identified 431 genes that potentially encode CWDEs. The 431 proteins contain 65 different CAZyme modules. Together, this cohort of $431 \mathrm{CWDEs}$ has the capacity to provide $P$. parasitica with the ability to degrade all major plant cell wall components. In the study reported in the present paper, each of the $431 \mathrm{CWDE}$ candidates was subjected to an in-depth bioinformatic analysis, with the goal of determining its enzymatic activity and possible substrate(s). Despite the difficulties in interpreting function from primary protein sequence, this individualized attention has not only highlighted annotation errors that are being perpetuated in successive studies but has also allowed the likely enzyme activity and targeted substrate to be deduced for many $P$. parasitica CWDEs.

In order to function in plant cell wall degradation, pathogen enzymes must be secreted and move through the pathogen cell wall to gain access to the plant cell wall. Most (337, 78\%) of the 431 putative P. parasitica CWDE had a classical secretion SP at their N-terminus. A further 67 (16\%) had sequences associated with nonclassical protein secretion. Only $23(5 \%)$ proteins, for which full-length sequence data were available, lacked any form of secretion sequence. Although initially controversial, the secretion of eukaryotic and prokaryotic proteins lacking a classical signal peptide is now well documented $[49,151]$. To date, no simple motif associated with non-classical secretion has been found but together a set of about six features of the amino acid sequence allow prediction of non-classical secretion [49]. Most non-classical secretory proteins are constitutively secreted but a number of mammalian proteins that undergo regulated secretion have also been shown to follow a non-classical pathway [152]. Information from studies of the role of non-classical secretion of CWDEs is not yet available.
One hundred of the proteins with, plus an additional one without, secretion sequences, contained a TMD or a GPI anchor. While on the one hand, possession of TMDs or GPI anchors may anchor the protein to the $P$. parasitica plasma membrane, recent evidence indicates that proteins with these motifs can be released from the membrane $[153,154]$. In some cases, modification of the GPI anchor results in binding of the protein to polysaccharides [155]. Biotrophic pathogens are known to have significantly fewer CWDEs than hemibiotrophs and necrotrophs, but there is little understanding of the protein attributes that might limit the movement of CWDEs and hence the degree of tissue maceration. It is known that the $\mathrm{pH}$ of the wall and isoelectric point of CWDEs will affect their mobility [156]. Perhaps modification of GPI anchors on CWDEs might be another means to regulate their movement within the plant cell wall.

The majority $(90 \%)$ of $P$. parasitica CWDEs contain a single CAZyme module. Only $13 P$. parasitica CWDEs have modules of different types and 37 have multiple copies of the same module. This situation is in contrast to that in fungal phytopathogens where, for example, proteins that contain a CBM module usually also include a catalytic module $[22,78,92]$. The significance of the presence of so few proteins containing both CBM and catalytic CAZyme modules in terms of $P$. parasitica pathogenicity remains to be determined, however, a CBM1 gene [PPTG_06045] is one of the most highly expressed genes during the infection of a susceptible host plant (LM Blackman, P Torreña, DP Cullerne, J Taylor and AR Hardham, unpublished observations).

Previous comparative studies of CWDEs in phytopathogenic fungi have shown that the complement of enzymes in terms of the CAZyme families represented and the numbers of proteins within a particular family are often very different in different organisms. The results of our characterization of the CWDE complement in $P$. parasitica add further data to extend this observation, and highlight some especially interesting differences between $P$. parasitica, or the Oomycetes in general, and fungal phytopathogens. The CBM CAZyme class is a case in point. In $P$. parasitica, as in $P$. ramorum and $P$. sojae, of the total of 55-61 CBM proteins, about $25 \%$ belong to CBM1 and 25\% to the CBM63 families, members of which bind to cellulose. Within hemibiotrophic and necrotrophic fungal species, apart from CBMs that target chitin, CBM1 is consistently the largest CBM family, often containing $25-50 \%$ of the total non-chitindirected CBMs $[30,31,70,71]$. In contrast to the situation in Phytophthora species, there are usually only 1-3 CBM63 proteins in these fungi.

Another striking difference between $P$. parasitica and fungal phytopathogens is presented by the complements of enzymes that degrade pectin. The degradation of 
Table 4 A summary of the numbers of carbohydrate-active proteins identified in $P$. parasitica and $P$. infestans in the current study and comparison of these data with those from three previous studies of $P$. infestans

\begin{tabular}{|c|c|c|c|c|c|c|c|c|c|c|c|c|c|c|}
\hline \multirow[b]{2}{*}{ CAZymes } & \multicolumn{4}{|c|}{ P. parasitica (current study) } & \multicolumn{4}{|c|}{ P. infestans (current study) } & \multicolumn{2}{|c|}{ P. infestans [31] } & \multicolumn{2}{|c|}{ P. infestans [29] } & \multicolumn{2}{|c|}{ P. infestans [149] } \\
\hline & $\begin{array}{l}\text { CAZyme } \\
\text { families }\end{array}$ & $\begin{array}{l}\text { CAZyme } \\
\text { modules }\end{array}$ & $\begin{array}{l}\text { CWDE } \\
\text { families }\end{array}$ & $\begin{array}{l}\text { CWDE } \\
\text { proteins }\end{array}$ & $\begin{array}{l}\text { CAZyme } \\
\text { families }\end{array}$ & $\begin{array}{l}\text { CAZyme } \\
\text { modules }\end{array}$ & $\begin{array}{l}\text { CWDE } \\
\text { families }\end{array}$ & $\begin{array}{l}\text { CWDE } \\
\text { proteins }\end{array}$ & $\begin{array}{l}\text { CAZyme } \\
\text { families }\end{array}$ & $\begin{array}{l}\text { CAZyme } \\
\text { modules }\end{array}$ & $\begin{array}{l}\text { CAZyme } \\
\text { families }\end{array}$ & $\begin{array}{l}\text { CAZyme } \\
\text { proteins }\end{array}$ & $\begin{array}{l}\text { CAZyme } \\
\text { families }\end{array}$ & $\begin{array}{l}\text { CAZyme } \\
\text { proteins }\end{array}$ \\
\hline$\overline{C B M}$ & 17 & 85 & 14 & 48 & 16 & 74 & 12 & 53 & 12 & 45 & na & na & na & 19 \\
\hline $\mathrm{AA}$ & 8 & 43 & 4 & 13 & 8 & 42 & 4 & 13 & na & na & na & na & na & na \\
\hline CE & 12 & 113 & 8 & 46 & 12 & 90 & 8 & 38 & 12 & 81 & 8 & 49 & na & 47 \\
\hline $\mathrm{GH}$ & 37 & 293 & 34 & 280 & 36 & 275 & 35 & 265 & 34 & 261 & 34 & 244 & na & 216 \\
\hline GT & 29 & 169 & na & na & 30 & 158 & na & na & 27 & 142 & 22 & 83 & na & 64 \\
\hline PL & 4 & 47 & 3 & 44 & 5 & 67 & 3 & 54 & 3 & 57 & 3 & 59 & na & 59 \\
\hline
\end{tabular}

na: data not available.

In the current study, CAZyme families and CAZyme modules were initially identified using dbCAN, BLAST, keyword and domain searches. Subsequent in-depth bioinformatic analyses of individual genes indicated that some CAZymes were unlikely to be true CWDEs, leading to a lower number of CWDE families than CAZyme families. Our data show that the numbers of CWDE families and CWDE proteins in each CAZyme class are remarkably similar in $P$. parasitica and $P$. infestans. Comparison of our $P$. infestans data with those from the other $P$. infestans studies exemplify the variation in CAZyme annotation achieved following different approaches and conducted at different times. 
pectin is thought to be the first step in a cascade of CWDE activity $[70,157,158]$. Pectin degradation may increase wall porosity and expose other wall polysaccharides, thereby facilitating the action of other pathogen enzymes. A broad spectrum of pectin-degrading enzymes is believed to be required in order to degrade the diversity of pectins found in plant cell walls $[159,160]$. Around 25\% (108) of P. parasitica CWDEs are directed solely towards pectin degradation and this number increases to $50 \%$ (208) if proteins in families with multiple targets are included. Of the pectin-directed enzymes in $P$. parasitica, 44 are PLs and 35 are CEs. Similar numbers occur in other Phytophthora species $[29,150,161]$. This situation may be compared to that in the fungi which typically have fewer than 20 PLs and 14 CEs [69-71,162]. In fungal pathogens, the pectin degrading enzymes are predominantly GH proteins $[69-71,163,164]$.

A third interesting comparison between Oomycete and fungal pathogens concerns the numbers of CWDEs directed towards the degradation of $\beta$-1,3-glucans. The deposition of $\beta-1,3$-glucans, in the form of callose, is an integral part of the basal plant defence response [165-167], and thus an ability to degrade callose could be an important attribute for successful infection. The $P$. parasitica genome contains 14 GH72 and 16 GH81 proteins that are thought to specifically degrade $\beta$-1,3-glucans. Fungal phytopathogens studied to date, on the other hand, have 1-8 GH72 and 0-3 GH81 proteins [69-71,162]. These fungi may have up to about 4 or $6 \beta$-1,3-glucanases in GH55 and GH64 families, respectively. Phytophthora cell walls themselves contain $\beta$-1,3-glucans $[77,129]$, so perhaps some of the $P$. parasitica $\beta-1,3$-glucanases are involved in pathogen wall modifications. However, it is still pertinent to ask if the larger numbers of $\beta$-1,3-glucanases in the Oomycetes mean that these organisms are better equipped to degrade the callose that is rapidly deposited in wall appositions at the infection site? An answer to this, and many other questions on CWDE function, requires further information, in particular that arising from transcriptome and protein localization studies.

\section{Additional files}

Additional file 1: Putative CAZyme modules identified by dbCAN analysis of predicted $P$. parasitica INRA-310 (V2) proteins. This output gives the E-value of the comparison of the dbCAN conserved domain determined by Hidden Markov Models and the signature domain of the queried protein. Columns four and five show the start and end of the aligned region within the conserved domain. Column six shows the fraction of the conserved domain covered by the P. parasitica signature domain. Columns seven and eight show the location of the signature domain within the P. parasitica protein. Five proteins from alternatively spliced transcripts (T1) that contained CAZyme modules were omitted from the analysis as these transcript variations did not result in different proteins. Where a protein was different in the most recent version of the annotated genome [46], the newer entry was used and these are indicated by (V3). Proteins that appeared to be incorrectly annotated as seen by missing $5^{\prime}$ or $3^{\prime}$ sequence data or to have incorrectly placed introns (as indicated by comparisons with EST data or genomic sequence data from another P. parasitica isolate), were manually curated and re-analyzed. Notes on proteins that appeared to be CAZymes but had greater homology to other proteins are included in the Comments column. Any protein with a dbCAN E-value $>\mathrm{e}-10$ or an aligned coverage fraction $<0.5$ were further scrutinised to ensure that no putative CWDEs were incorrectly identified. Gray shading indicates that the predicted protein contains more than one CAZyme module of the same type. Green shading indicates that the predicted protein contains CAZyme modules of different types. TMD indicates a transmembrane domain.

Additional file 2: Details of putative $P$. parasitica INRA-310 (V2) CWDEs and their potential substrates. Truncated proteins and the $P$. parasitica strains used for analysis of specific proteins are indicated (P1569, P1976, P10297 and CJ01A1). HG = homogalacturonan, RGI = rhamnogalacturonan I, AGP = arabinogalactan proteins, GA = galacturonic acid. V3 = protein from $P$. parasitica INRA-310 (V3) used for analysis. The number of CAZyme modules and their E-values from dbCAN analysis or other features such as a Pfam domain are shown. SP = secretion signal determined by SignalP; "SP" = secretion signal if alternative nearby start codon is used; NN scores $\geq 0.5=$ non-classical secretion; TMD = transmembrane domain, the location of which is indicated by $\mathrm{N}$ or $\mathrm{C} ; \mathrm{GPI}=$ glycosylphosphatidylinositol-anchored, ? = complete analysis was not possible due to truncated proteins in all P. parasitica strains and it was not possible to determine the likely substrate.

Additional file 3: Putative CAZyme modules identified by dbCAN analysis of predicted $P$. infestans proteins. The output gives the Evalue of the comparison of the dbCAN conserved domain determined by Hidden Markov Models and the signature domain of the queried protein. Columns four and five show the start and end of the aligned region within the conserved domain. Column six shows the fraction of the conserved domain covered by the $P$. infestans signature domain. Columns seven and eight show the location of the signature domain within the $P$. infestans protein. Gray shading indicates that the predicted protein contains more than one CAZyme module of the same type. Green shading indicates that he predicted protein contains CAZyme modules of different types.

Additional file 4: Details of putative $P$. infestans CWDEs. The number of CAZyme modules and their E-values from dbCAN analysis or other features such as a Pfam domain are shown. Truncated proteins are indicated. SP = secretion signal determined by SignalP; "SP" = secretion signal if alternative nearby start codon is used; NN scores $\geq 0.5=$ nonclassical secretion; $\mathrm{TMD}=$ transmembrane domain, the location of which is indicated by $\mathrm{N}$ or $\mathrm{C}_{;} \mathrm{GPI}=$ glycosylphosphatidylinositol-anchored.

\section{Abbreviations}

AA: Auxiliary activities; AGP: Arabinogalactan protein; CAT: CAZymes Analysis Toolkit; CAZyme: Carbohydrate-Active enzyme; CBM: Carbohydrate binding module; CE: Carbohydrate esterase; CWDE: Cell wall degrading enzyme; dbCAN: Carbohydrate-active enzyme Annotation; GH: Glycoside hydrolase; GPI: Glycosylphosphatidyl inositol; GT: Glycosyl transferase;

HG: Homogalacturonan; NCBI: National Center for Biotechnology Information; PGA: Polygalacturonic acid; PL: Polysaccharide lyase; PPTG: Phytophthora parasitica INRA-310 (V2) protein; PITG: Phytophthora infestans protein; RGI: Rhamnogalacturonan I; RGIl: Rhamnogalacturonan II; SP: Secretion signal; TMD: Transmembrane domain.

\section{Competing interests}

The authors declare that they have no competing interests.

\section{Authors' contributions}

LMB did the data analysis and drafted the manuscript. DC was involved in the initial analysis of two GH families and helped in the final draft of the manuscript. ARH conceived the study, guided data analysis, and helped draft and write the manuscript. All authors have read and agreed to the final manuscript. 


\section{Acknowledgements}

The authors thank Brett Tyler, Carsten Russ, Franck Panabières and Weixing Shan for making the $P$. parasitica genome sequences available prior to publication. This study was conducted with the support of the Australian Research Council.

\section{Author details}

${ }^{1}$ Plant Science Division, Research School of Biology, College of Medicine, Biology and Environment, The Australian National University, Canberra ACT 0200, Australia. ${ }^{2}$ Current address: CSIRO, Agriculture Flagship, Canberra ACT, 2601, Australia.

Received: 27 March 2014 Accepted: 3 September 2014 Published: 11 September 2014

\section{References}

1. Liu H, Zhang S, Schell MA, Denny TP: Pyramiding unmarked deletions in Ralstonia solanacearum shows that secreted proteins in addition to plant cell-wall-degrading enzymes contribute to virulence. Mol Plant Microbe Interact 2005, 18:1296-1305.

2. Vorwerk S, Somerville S, Somerville C: The role of plant cell wall polysaccharide composition in disease resistance. Trends Plant Sci 2004, 9:203-209.

3. Albersheim P, Darvill A, Roberts K, Sederoff R, Staehelin A: Biochemistry of the cell wall molecules. In Plant Cell Walls from Chemistry to Biology. New York: Garland Science; 2011:68-118.

4. Caffall KH, Mohnen D: The structure, function, and biosynthesis of plant cell wall pectic polysaccharides. Carbohydr Res 2009, 344:1879-1900.

5. Somerville C, Bauer S, Brininstool G, Facette M, Hamann T, Milne J, Osborne E, Paredez A, Persson S, Raab T, Vorwerk S, Youngs H: Toward a systems approach to understanding plant cell walls. Science 2004, 306:2206-2211.

6. Scheller HV, Ulvskov P: Hemicelluloses. Annu Rev Plant Biol 2010, 61:263-289.

7. Vincken J-P, Schols HA, Oomen RJFJ, McCann MC, Ulvskov P, Voragen AGJ, Visser RGF: If homogalacturonan were a side chain of rhamnogalacturonan I. Implications for cell wall architecture. Plant Physiol 2003, 132:1781-1789.

8. Mohnen D: Pectin structure and biosynthesis. Curr Opin Plant Biol 2008 , 11:266-277.

9. Ridley BL, O'Neill MA, Mohnen D: Pectins: structure, biosynthesis, and oligogalacturonide-related signaling. Phytochemistry 2001, 57:929-967.

10. Pabst M, Fischl RM, Brecker L, Morelle W, Fauland A, Köfeler H, Altmann F, Léonard R: Rhamnogalacturonan II structure shows variation in the side chains monosaccharide composition and methylation status within and across different plant species. Plant J 2013, 76:61-72.

11. Wilson IB: Glycosylation of proteins in plants and invertebrates. Curr Opin Struct Biol 2002, 12:569-577.

12. Garbe J, Collin M: Bacterial hydrolysis of host glycoproteins - powerfu protein modification and efficient nutrient acquisition. $J$ Innate Immun 2012, 4:121-131.

13. Seifert GJ, Roberts K: The biology of arabinogalactan proteins. Annu Rev Plant Biol 2007, 58:137-161.

14. Williamson G, Kroon PA, Faulds CB: Hairy plant polysaccharides: a close shave with microbial esterases. Microbiology 1998, 144:2011-2023.

15. Hückelhoven R: Cell wall-associated mechanisms of disease resistance and susceptibility. Annu Rev Phytopathol 2007, 45:101-127.

16. Chen XY, Kim JY: Callose synthesis in higher plants. Plant Signal Behav 2009, 4:489-492

17. Franková L, Fry SC: Biochemistry and physiological roles of enzymes that 'cut and paste' plant cell-wall polysaccharides. J Exp Bot 2013, 64:3519-3550

18. van den Brink J, de Vries RP: Fungal enzyme sets for plant polysaccharide degradation. Appl Microbiol Biotechnol 2011, 91:1477-1492.

19. Henrissat B, Coutinho PM, Davies GJ: A census of carbohydrate-active enzymes in the genome of Arabidopsis thaliana. Plant Mol Biol 2001, 47:55-72.

20. Cantarel BL, Coutinho PM, Rancurel C, Bernard T, Lombard V, Henrissat B: The Carbohydrate-Active EnZymes database (CAZy): an expert resource for Glycogenomics. Nucleic Acids Res 2009, 37:D233-D238.
21. Levasseur A, Drula E, Lombard V, Coutinho PM, Henrissat B: Expansion of the enzymatic repertoire of the CAZy database to integrate auxiliary redox enzymes. Biotechnol Biofuels 2013, 6:41

22. Boraston AB, Bolam DN, Gilbert HJ, Davies GJ: Carbohydrate-binding modules: fine-tuning polysaccharide recognition. Biochem J 2004, 382:769-781.

23. Aspeborg H, Coutinho PM, Wang Y, Brumer H, Henrissat B: Evolution, substrate specificity and subfamily classification of glycoside hydrolase family 5 (GH5). BMC Evol Biol 2012, 12:186.

24. Horn SJ, Vaaje-Kolstad G, Westereng B, Eijsink VG: Novel enzymes for the degradation of cellulose. Biotechnol Biofuels 2012, 5:45

25. Lombard V, Bernard T, Rancurel C, Brumer H, Coutinho PM, Henrissat B: A hierarchical classification of polysaccharide lyases for glycogenomics. Biochem J 2010, 432:437-444.

26. Henrissat B, Davies GJ: Glycoside hydrolases and glycosyltransferases. Families, modules, and implications for genomics. Plant Physiol 2000, 124:1515-1519.

27. Hardham AR, Cahill DM: The role of oomycete effectors in plantpathogen interactions. Funct Plant Biol 2010, 37:919-925.

28. Jiang $\mathrm{RH}$, Tyler BM: Mechanisms and evolution of virulence in oomycetes. Annu Rev Phytopathol 2012, 50:295-318.

29. Ospina-Giraldo MD, Griffith JG, Laird EW, Mingora C: The CAZyome of Phytophthora spp.: a comprehensive analysis of the gene complement coding for carbohydrate-active enzymes in species of the genus Phytophthora. BMC Genomics 2010, 11:525.

30. Larroque M, Barriot R, Bottin A, Barre A, Rouge P, Dumas B, Gaulin E: The unique architecture and function of cellulose-interacting proteins in oomycetes revealed by genomic and structural analyses. BMC Genomics 2012, 13:605.

31. Zerillo MM, Adhikari BN, Hamilton JP, Buell CR, Lévesque CA, Tisserat N: Carbohydrate-active enzymes in Pythium and their role in plant cell wall and storage polysaccharide degradation. PLOS One 2013, 8:e72572

32. Savory EA, Adhikari BN, Hamilton JP, Vaillancourt B, Buell CR, Day B: mRNA seq analysis of the Pseudoperonospora cubensis transcriptome during cucumber (Cucumis sativus L.) infection. PLoS One 2012, 7:e35796.

33. Phytophthora parasitica INRA-310 Sequencing Project, Broad Institute of Harvard and MIT. http://www.broadinstitute.org/.

34. Database for Carbohydrate-active enzyme ANnotation. http://csbl.bmb.uga. edu/dbCAN/index.php

35. Yin $Y$, Mao $X$, Yang J, Chen $X$, Mao F, Ying X: dbCAN: a web resource for automated carbohydrate-active enzyme annotation. Nucl Acids Res 2012, 40:W445-W451.

36. MyHits. http://myhits.isb-sib.ch.

37. Sigrist CJ, de Castro E, Cerutti L, Cuche BA, Hulo N, Bridge A, Bougueleret L, Xenarios I: New and continuing developments at PROSITE. Nucleic Acids Res 2013, 41:D344-D347.

38. The PROSITE database. http://prosite.expasy.org/prosite.html.

39. National Center for Biotechnology Information. http://www.ncbi.nlm.nih.gov

40. Pfam 27.0. http://pfam.sanger.ac.uk.

41. Punta M, Coggill PC, Eberhardt RY, Mistry J, Tate J, Boursnell C, Pang N, Forslund K, Ceric G, Clements J, Heger A, Holm L, Sonnhammer ELL, Eddy SR, Bateman A, Finn RD: The Pfam protein families database. Nucleic Acids Res 2012, 40:D290-D301.

42. Altschul SF, Madden TL, Schaffer AA, Zhang J, Zhang Z, Miller W, Lipman DJ: Gapped BLAST and PSI-BLAST: a new generation of protein database search programs. Nucleic Acids Res 1997, 25:3389-3402.

43. The Carbohydrate-Active enZYmes Database. http://www.cazy.org]

44. Park BH, Karpinets TV, Syed MH, Leuze MR, Uberbacher EC: CAZymes Analysis Toolkit (CAT): Web service for searching and analyzing carbohydrate-active enzymes in a newly sequenced organism using CAZy database. Glycobiology 2010, 20:1574-1584.

45. CAZYmes Analysis Toolkit. http://mothra.ornl.gov/cgi-bin/cat/cat.cgi.

46. INRA-310 Sequencing Project, Broad Institute of Harvard and MIT (V3). https:// olive.broadinstitute.org/projects/phytophthora_parasitica].

47. Petersen TN, Brunak S, von Heijne G, Nielsen H: SignalP 4.0: discriminating signal peptides from transmembrane regions. Nat Methods 2011, 8:785-786.

48. SignalP 4.1 Server. http://www.cbs.dtu.dk/services/SignalP/.

49. Bendtsen JD, Jensen LJ, Blom N, von Heijne G, Brunak S: Feature-based prediction of non-classical and leaderless protein secretion. Protein Eng Des Sel 2004, 17:349-356. 
50. SecretomeP 1.0f. http://www.cbs.dtu.dk/services/SecretomeP/.

51. Bendtsen JD, Nielsen H, von Heijne G, Brunak S: Improved prediction of signal peptides: SignalP 3.0. J Mol Biol 2004, 340:783-795.

52. Soanes DM, Richards TA, Talbot NJ: Insights from sequencing fungal and oomycete genomes: what can we learn about plant disease and the evolution of pathogenicity? Plant Cell 2007, 19:3318-3326.

53. A combined transmembrane topology and signal peptide predictor. http:// phobius.sbc.su.se.

54. Krogh A, Larsson B, von Heijne G, Sonnhammer EL: Predicting transmembrane protein topology with a hidden Markov model: application to complete genomes. J Mol Biol 2001, 305:567-580.

55. TMHMM Server $v$. 2.0. http://www.cbs.dtu.dk/services/TMHMM/.

56. Pierleoni A, Martelli PL, Casadio R: PredGPI: a GPI-anchor predictor. BMC Bioinformatics 2008, 9:392.

57. PredGPI predictor. http://gpcr.biocomp.unibo.it/predgpi/pred.htm

58. Thompson JD, Higgins DG, Gibson TJ: CLUSTAL W: improving the sensitivity of progressive multiple sequence alignment through sequence weighting, position-specific gap penalties and weight matrix choice. Nucleic Acids Res 1994, 11:4673-4680.

59. Network Protein Sequence Analysis: CLUSTALW. https://npsa-prabi.ibcp.fr/cgibin/npsa_automat.pl?page=npsa_clustalw.html.

60. Sander C, Schneider R: Database of homology-derived protein structures and the structural meaning of sequence alignment. Proteins 1991, 9:56-68

61. Lopez-Casado G, Urbanowicz BR, Damasceno CM, Rose JK: Plant glycosyl hydrolases and biofuels: a natural marriage. Curr Opin Plant Biol 2008, 11:329-337.

62. Hakkinen M, Arvas M, Oja M, Aro N, Penttila M, Saloheimo M, Pakula TM: Reannotation of the CAZy genes of Trichoderma reesei and transcription in the presence of lignocellulosic substrates. Microb Cell Fact 2012, 11:134

63. Davies GJ, Gloster TM, Henrissat B: Recent structural insights into the expanding world of carbohydrate-active enzymes. Curr Opin Struct Biol 2005, 15:637-645.

64. Minic Z: Physiological roles of plant glycoside hydrolases. Planta 2008 227:723-740.

65. Mertz B, Gu X, Reilly PJ: Analysis of functional divergence within two structurally related glycoside hydrolase families. Biopolymers 2009, 91:478-495.

66. Ketudat Cairns JR, Esen A: $\beta$-Glucosidases. Cell Mol Life Sci 2010, 67:3389-3405

67. Kuntothom T, Luang S, Harvey AJ, Fincher GB, Opassiri R, Hrmova M, Ketudat Cairns JR: Rice family GH1 glycoside hydrolases with $\beta$-Dglucosidase and $\beta$-D-mannosidase activities. Arch Biochem Biophys 2009, 491:85-95.

68. St John FJ, González JM, Pozharski E: Consolidation of glycosyl hydrolase family 30: A dual domain 4/7 hydrolase family consisting of two structurally distinct groups. FEBS Lett 2010, 584:4435-4441.

69. Battaglia E, Benoit I, van den Brink J, Wiebenga A, Coutinho PM, Henrissat B, de Vries RP: Carbohydrate-active enzymes from the zygomycete fungus Rhizopus oryzae: a highly specialized approach to carbohydrate degradation depicted at genome level. BMC Genomics 2011, 12:38

70. O'Connell RJ, Thon MR, Hacquard S, Amyotte SG, Kleemann J, Torres MF, Damm U, Buiate EA, Epstein L, Alkan N, Altmuller J, Alvarado-Balderrama L Bauser CA, Becker C, Birren BW, Chen Z, Choi J, Crouch JA, Duvick JP, Farman MA, Gan P, Heiman D, Henrissat B, Howard RJ, Kabbage M, Koch C, Kracher B, Kubo Y, Law AD, Lebrun MH, et al: Lifestyle transitions in plant pathogenic Colletotrichum fungi deciphered by genome and transcriptome analyses. Nat Genet 2012, 44:1060-1065.

71. Zhao Z, Liu H, Wang C, Xu JR: Comparative analysis of fungal genomes reveals different plant cell wall degrading capacity in fungi. $B M C$ Genomics 2013, 14:274

72. Minic Z, Jouanin L: Plant glycoside hydrolases involved in cell wall polysaccharide degradation. Plant Physiol Biochem 2006, 44:435-449.

73. Wymelenberg AV, Denman S, Dietrich D, Bassett J, Yu X, Atalla R, Predki P, Rudsander $U$, Teeri $\Pi$, Cullen D: Transcript analysis of genes encoding a family 61 endoglucanase and a putative membrane-anchored family 9 glycosyl hydrolase from Phanerochaete chrysosporium. Appl Environ Microbiol 2002, 68:5765-5768

74. Nicol F, His I, Jauneau A, Vernhettes S, Canut H, Höfte H: A plasma membrane-bound putative endo-1,4- $\beta$-D-glucanase is required for normal wall assembly and cell elongation in Arabidopsis. EMBO J 1998, 17:5563-5576

75. Brunner F, Wirtz W, Rose JK, Darvill AG, Govers F, Scheel D, Nürnberger T: A $\beta$-glucosidase/xylosidase from the phytopathogenic oomycete, Phytophthora infestans. Phytochemistry 2002, 59:689-696.

76. Costanzo S, Ospina-Giraldo MD, Deahl KL, Baker CJ, Jones RW: Alternate intron processing of family 5 endoglucanase transcripts from the genus Phytophthora. Curr Genet 2007, 52:115-123.

77. Mélida H, Sandoval-Sierra JV, Diéguez-Uribeondo J, Bulone V: Analyses of extracellular carbohydrates in Oomycetes unveil the existence of three different cell wall types. Eukaryot Cell 2013, 12:194-203.

78. Guillén D, Sánchez S, Rodríguez-Sanoja R: Carbohydrate-binding domains: multiplicity of biological roles. Appl Microbiol Biotechnol 2010, 85:1241-1249.

79. Li XL, Chen H, Ljungdahl LG: Two cellulases, CelA and CelC, from the polycentric anaerobic fungus Orpinomyces strain $\mathrm{PC}-2$ contain N-terminal docking domains for a cellulase-hemicellulase complex. Appl Environ Microbiol 1997, 63:4721-4728.

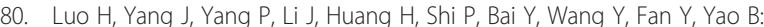
Gene cloning and expression of a new acidic family 7 endo- $\beta-1,3-1,4-$ glucanase from the acidophilic fungus Bispora sp. MEY-1. Appl Microbiol Biotechnol 2010, 85:1015-1023.

81. Goedegebuur F, Fowler T, Phillips J, van der Kley P, van Solingen P, Dankmeyer L, Power SD: Cloning and relational analysis of 15 novel fungal endoglucanases from family 12 glycosyl hydrolase. Curr Genet 2002, 41:89-98.

82. Master ER, Zheng Y, Storms R, Tsang A, Powlowski J: A xyloglucan-specific family 12 glycosyl hydrolase from Aspergillus niger: recombinant expression, purification and characterization. Biochem J 2008, 411:161-170.

83. Lafond M, Navarro D, Haon M, Couturier M, Berrin JG: Characterization of a broad-specificity $\beta$-glucanase acting on $\beta-(1,3)-, \beta-(1,4)-$, and $\beta-(1,6)-$ glucans that defines a new glycoside hydrolase family. Appl Environ Microbiol 2012, 78:8540-8546.

84. Hemsworth GR, Taylor EJ, Kim RQ, Gregory RC, Lewis SJ, Turkenburg JP, Parkin A, Davies GJ, Walton PH: The copper active site of CBM33 polysaccharide oxygenases. J Am Chem Soc 2013, 135:6069-6077.

85. Forsberg Z, Vaaje-Kolstad G, Westereng B, Bunaes AC, Stenstrom Y MacKenzie A, Sorlie M, Horn SJ, Eijsink VG: Cleavage of cellulose by a CBM33 protein. Protein Sci 2011, 20:1479-1483.

86. Li X, Beeson WT, Phillips CM, Marletta MA, Cate JH: Structural basis for substrate targeting and catalysis by fungal polysaccharide monooxygenases. Structure 2012, 20:1051-1061.

87. Lee MH, Lai WL, Lin SF, Hsu CS, Liaw SH, Tsai YC: Structural characterization of glucooligosaccharide oxidase from Acremonium strictum. Appl Environ Microbiol 2005, 71:8881-8887.

88. Boraston $A B$, Tomme $P$, Amandoron EA, Kilburn DG: A novel mechanism of xylan binding by a lectin-like module from Streptomyces lividans xylanase 10A. Biochem J 2000, 350:933-941.

89. Georgelis N, Yennawar NH, Cosgrove DJ: Structural basis for entropydriven cellulose binding by a type-A cellulose-binding module (CBM) and bacterial expansin. Proc Natl Acad Sci U S A 2012, 109:14830-14835.

90. Mateos FV, Rickauer M, Esquerre-Tugaye MT: Cloning and characterization of a cDNA encoding an elicitor of Phytophthora parasitica var. nicotianae that shows cellulose-binding and lectin-like activities. Mol Plant Microbe Interact 1997, 10:1045-1053.

91. Georgelis N, Nikolaidis N, Cosgrove DJ: Biochemical analysis of expansinlike proteins from microbes. Carbohydr Polym 2014, 100:17-23.

92. Hashimoto H: Recent structural studies of carbohydrate-binding modules. Cell Mol Life Sci 2006, 63:2954-2967.

93. Colletotrichum Sequencing Project, Broad Institute of Harvard and MIT. http:// www.broadinstitute.org/annotation/genome/colletotrichum_group/ MultiHome.html.

94. Gilbert HJ, Stalbrand H, Brumer H: How the walls come crumbling down: recent structural biochemistry of plant polysaccharide degradation. Curr Opin Plant Biol 2008, 11:338-348.

95. Kotake $T$, Hirata N, Degi $Y$, Ishiguro M, Kitazawa K, Takata R, Ichinose H, Kaneko S, Igarashi K, Samejima M, Tsumuraya Y: Endo- $\beta$-1,3-galactanase from winter mushroom Flammulina velutipes. J Biol Chem 2011, 286:27848-27854 
96. Steczkiewicz K, Knizewski L, Rychlewski L, Ginalski K: TOS1 is circularly permuted 1,3- $\beta$-glucanase. Cell Cycle 2010, 9:201-204.

97. Collins T, Gerday C, Feller G: Xylanases, xylanase families and extremophilic xylanases. FEMS Microbiol Rev 2005, 29:3-23.

98. Suzuki S, Fukuoka M, Ookuchi H, Sano M, Ozeki K, Nagayoshi E, Takii Y, Matsushita M, Tada S, Kusumoto K-I, Kashiwagi Y: Characterization of Aspergillus oryzae glycoside hydrolase family $43 \beta$-xylosidase expressed in Escherichia coli. J Biosci Bioeng 2010, 109:115-117.

99. Ichinose H, Kotake T, Tsumuraya Y, Kaneko S: Characterization of an endoß-1,6-galactanase from Streptomyces avermitilis NBRC14893. Appl Environ Microbiol 2008, 74:2283-2379.

100. Biely P: Microbial carbohydrate esterases deacetylating plant polysaccharides. Biotechnol Adv 2012, 30:1575-1588.

101. de Vries RP, VanKuyk PA, Kester HC, Visser J: The Aspergillus niger faeB gene encodes a second feruloyl esterase involved in pectin and xylan degradation and is specifically induced in the presence of aromatic compounds. Biochem J 2002, 363:377-386.

102. Dalrymple BP, Cybinski DH, Layton I, MCSweeney CS, Xue GP, Swadling YJ, Lowry JB: Three Neocallimastix patriciarum esterases associated with the degradation of complex polysaccharides are members of a new family of hydrolases. Microbiology 1997, 143:2605-2614.

103. Randall TA, Dwyer RA, Huitema E, Beyer K, Cvitanich C, Kelkar H, Fong AMVA, Gates K, Roberts S, Yatzkan E, Gaffney T, Law M, Testa A, TortoAlalibo T, Zhang M, Zheng L, Mueller E, Windass J, Binder A, Birch PRJ, Gisi U, Govers F, Gow NA, Mauch F, Van WP, Judelson HS: Large-scale gene discovery in the oomycete Phytophthora infestans reveals likely components of phytopathogenicity shared with true fungi. Mol Plant Microbe Interact 2005, 18:229-243.

104. Puchart V, Gariepy MC, Shareck F, Dupont C: Identification of catalytically important amino acid residues of Streptomyces lividans acetylxylan esterase A from carbohydrate esterase family 4. Biochim Biophys Acta 2006, 1764:263-274.

105. Blair DE, van Aalten DM: Structures of Bacillus subtilis PdaA, a family 4 carbohydrate esterase, and a complex with $\mathrm{N}$-acetyl-glucosamine. FEBS Lett 2004, 570:13-19.

106. Shallom D, Shoham Y: Microbial hemicellulases. Curr Opin Microbiol 2003, 6:219-2128

107. Pouvreau L, Jonathan MC, Kabel MA, Hinz SW, Gruppen H, Schols HA: Characterization and mode of action of two acetyl xylan esterases from Chrysosporium lucknowense $\mathrm{C} 1$ active towards acetylated xylans. Enzyme Microb Technol 2011, 49:312-320.

108. Soliday CL, Flurkey WH, Okita TW, Kolattukudy PE: Cloning and structure determination of cDNA for cutinase, an enzyme involved in fungal penetration of plants. Proc Natl Acad Sci U S A 1984, 81:3939-3943.

109. Belbahri L, Calmin G, Mauch F, Andersson JO: Evolution of the cutinase gene family: evidence for lateral gene transfer of a candidate Phytophthora virulence factor. Gene 2008, 408:1-8.

110. Pérez S, Rodríguez-Carvajal MA, Doco T: A complex plant cell wall polysaccharide: rhamnogalacturonan II, A structure in quest of a function. Biochimie 2003, 85:109-121.

111. Wu C-H, Yan H-Z, Liu L-F, Liou R-F: Functional characterization of a gene family encoding polygalacturonases in Phytophthora parasitica. Mol Plant Microbe Interact 2008, 21:480-489.

112. Yan HZ, Liou RF: Cloning and analysis of pppg1, an inducible endopolygalacturonase gene from the oomycete plant pathogen Phytophthora parasitica. Fungal Genet Biol 2005, 42:339-350.

113. Yadav V, Yadav PK, Yadav S, Yadav KDS: a-L-Rhamnosidase: A review. Process Biochem 2010, 45:1226-1235.

114. Itoh T, Ochiai A, Mikami B, Hashimoto W, Murata K: A novel glycoside hydrolase family 105: the structure of family 105 unsaturated rhamnogalacturonyl hydrolase complexed with a disaccharide in comparison with family 88 enzyme complexed with the disaccharide. J Mol Biol 2006, 360:573-585

115. Ahn YO, Zheng M, Bevan DR, Esen A, Shiu SH, Benson J, Peng HP, Miller JT, Cheng CL, Poulton JE, Shih MC: Functional genomic analysis of Arabidopsis thaliana glycoside hydrolase family 35. Phytochemistry 2007. 68:1510-1520

116. Vanholme B, Haegeman A, Jacob J, Cannoot B, Gheysen G: Arabinogalactan endo-1,4- $\beta$-galactosidase: a putative plant cell walldegrading enzyme of plant-parasitic nematodes. Nematology 2009, 11:739-747.
117. Miyanaga A, Koseki T, Miwa Y, Mese Y, Nakamura S, Kuno A, Hirabayashi J, Matsuzawa H, Wakagi T, Shoun H, Fushinobu S: The family 42 carbohydrate-binding module of family $54 \mathrm{a}$-L-arabinofuranosidase specifically binds the arabinofuranose side chain of hemicellulose. Biochem J 2006, 399:503-511.

118. de Wet BJ, Matthew MK, Storbeck KH, van Zyl WH, Prior BA: Characterization of a family $54 \mathrm{a}$-L-arabinofuranosidase from Aureobasidium pullulans. Appl Microbiol Biotechnol 2008, 77:975-983.

119. Garron ML, Cygler M: Structural and mechanistic classification of uronic acid-containing polysaccharide lyases. Glycobiology 2010, 20:1547-1573.

120. Wang H, Fu L, Zhang X: Comparison of expression, purification and characterization of a new pectate lyase from Phytophthora capsici using two different methods. BMC Biotechnol 2011, 11:32.

121. Fu L, Wang HZ, Feng BZ, Zhang XG: Cloning, expression, purification and initial analysis of a novel pectate lyase Pcpel1 from Phytophthora capsici. J Phytopathol 2013, 161:230-238.

122. McDonough MA, Kadirvelraj $R$, Harris P, Poulsen JC, Larsen S: Rhamnogalacturonan lyase reveals a unique three-domain modular structure for polysaccharide lyase family 4. FEBS Lett 2004, 565:188-194.

123. de Vries RP, Visser J: Aspergillus enzymes involved in degradation of plant cell wall polysaccharides. Microbiol Mol Biol Rev 2001, 65:497-522.

124. Gou JY, Miller LM, Hou G, Yu XH, Chen XY, Liu CJ: Acetylesterase-mediated deacetylation of pectin impairs cell elongation, pollen germination, and plant reproduction. Plant Cell 2012, 24:50-65.

125. Navarro-Fernández J, Martínez-Martínez I, Montoro-García S, García-Carmona F, Takami $H$, Sánchez-Ferrer A: Characterization of a new rhamnogalacturonan acetyl esterase from Bacillus halodurans C-125 with a new putative carbohydrate binding domain. J Bacterio/ 2008, 190:1375-1382.

126. Abbott DW, Eirin-Lopez JM, Boraston AB: Insight into ligand diversity and novel biological roles for family 32 carbohydrate-binding modules. Mol Biol Evol 2008, 25:155-167.

127. Martin-Cuadrado AB, Fontaine T, Esteban PF, del Dedo JE, de MedinaRedondo M, del Rey F, Latge JP, de Aldana CR: Characterization of the endo- $\beta-1,3-$ glucanase activity of $S$. cerevisiae Eng 2 and other members of the GH81 family. Fungal Genet Biol 2008, 45:542-553.

128. Song JM, Nam K, Sun YU, Kang MH, Kim CG, Kwon ST, Lee J, Lee YH: Molecular and biochemical characterizations of a novel arthropod endo$\beta-1,3-g l u c a n a s e$ from the Antarctic springtail, Cryptopygus antarcticus, horizontally acquired from bacteria. Comp Biochem Physiol B 2010, 155:403-412.

129. Enkerli K, Mims CW, Hahn MG: Immunogold localization of callose and other plant cell wall components in soybean roots infected with the oomycete Phytophthora sojae. Can J Bot 1997, 75:1509-1517.

130. Ragni E, Fontaine T, Gissi C, Latge JP, Popolo L: The Gas family of proteins of Saccharomyces cerevisiae: characterization and evolutionary analysis. Yeast 2007, 24:297-308.

131. Mouyna I, Fontaine T, Vai M, Monod M, Fonzi WA, Diaquin M, Popolo L, Hartland RP, Latge JP: Glycosylphosphatidylinositol-anchored glucanosyltransferases play an active role in the biosynthesis of the fungal cell wall. J Biol Chem 2000, 275:14882-14889.

132. Durand A, Hughes R, Roussel A, Flatman R, Henrissat B, Juge N: Emergence of a subfamily of xylanase inhibitors within glycoside hydrolase family 18. FEBS J 2005, 272:1745-1855.

133. Tzelepis GD, Melin P, Jensen DF, Stenlid J, Karlssona M: Functional analysis of glycoside hydrolase family 18 and 20 genes in Neurospora crassa. Fungal Genet Biol 2012, 49:717-730

134. Lefebvre F, Joly DL, Labbé C, Teichmann B, Linning R, Belzile F, Bakkeren G, Bélanger RR: The transition from a phytopathogenic smut ancestor to an anamorphic biocontrol agent deciphered by comparative wholegenome analysis. Plant Cell 2013, 25:1946-1959.

135. Buist G, Steen A, Kok J, Kuipers OP: LysM, a widely distributed protein motif for binding to (peptido)glycans. Mol Microbiol 2008, 68:838-847.

136. Gregg KJ, Zandberg WF, Hehemann JH, Whitworth GE, Deng L, Vocadlo DJ, Boraston $A B$ : Analysis of a new family of widely distributed metalindependent a-mannosidases provides unique insight into the processing of N-linked glycans. J Biol Chem 2011, 286:15586-15596.

137. Miyazaki T, Matsumoto Y, Matsuda K, Kurakata Y, Matsuo I, Ito Y, Nishikawa A, Tonozuka T: Heterologous expression and characterization of processing a-glucosidase I from Aspergillus brasiliensis ATCC 9642. Glycoconj J 2011, 28:563-571. 
138. Kato T, Fujita K, Takeuchi M, Kobayashi K, Natsuka S, Ikura K, Kumagai H, Yamamoto $\mathrm{K}$ : Identification of an endo- $\beta-\mathrm{N}$-acetylglucosaminidase gene in Caenorhabditis elegans and its expression in Escherichia coli. Glycobiology 2002, 12:581-587.

139. Ficko-Blean E, Boraston AB: Structural analysis of a bacterial exo-a-D-Nacetylglucosaminidase in complex with an unusual disaccharide found in class III mucin. Glycobiology 2012, 22:590-595.

140. Cacas J-L, Buré C, Furt F, Maalouf J-P, Badoc A, Cluzet S, Schmitter J-M, Antajan E, Mongrand S: Biochemical survey of the polar head of plant glycosylinositolphosphoceramides unravels broad diversity. Phytochemistry 2013, 96:191-200.

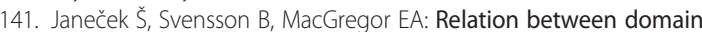
evolution, specificity, and taxonomy of the a-amylase family members containing a C-terminal starch-binding domain. Eur J Biochem 2003, 270:635-645.

142. Christiansen C, Abou Hachem M, Janecek S, Viksø-Nielsen A, Blennow A, Svensson B: The carbohydrate-binding module family 20 - diversity, structure, and function. FEBS J 2009, 276:5006-5029.

143. Moreira LR, Filho EX: An overview of mannan structure and mannandegrading enzyme systems. App/ Microbiol Biotechnol 2008, 79:165-178.

144. Larsbrink J, Izumi A, Ibatullin FM, Nakhai A, Gilbert HJ, Davies GJ, Brumer H: Structural and enzymatic characterization of a glycoside hydrolase family 31 a-xylosidase from Cellvibrio japonicus involved in xyloglucan saccharification. Biochem J 2011, 436:567-580.

145. Springer WR, Cooper DN, Barondes SH: Discoidin I is implicated in cellsubstratum attachment and ordered cell migration of Dictyostelium discoideum and resembles fibronectin. Cell 1984, 39:557-564.

146. Lammens W, Le Roy K, Schroeven L, Van Laere A, Rabijns A, Van den Ende W: Structural insights into glycoside hydrolase family 32 and 68 enzymes: functional implications. J Exp Bot 2009, 60:727-740.

147. Judelson HS, Tani S, Narayan RD: Metabolic adaptation of Phytophthora infestans during growth on leaves, tubers and artificial media. Mol Plant Pathol 2009, 10:843-855.

148. Phytophthora infestans: Sequencing Project, Broad Institute of Harvard and MIT. http://www.broadinstitute.org/.

149. Adhikari BN, Hamilton JP, Zerillo MM, Tisserat N, Lévesque CA, Buell CR: Comparative genomics reveals insight into virulence strategies of plant pathogenic oomycetes. PLoS One 2013, 8:e75072.

150. Ospina-Giraldo MD, McWalters J, Seyer L: Structural and functional profile of the carbohydrate esterase gene complement in Phytophthora infestans. Curr Genet 2010, 56:495-506.

151. Wang G, Chen H, Xia Y, Cui J, Gu Z, Song Y, Chen YQ, Zhang H, Chen W: How are the non-classically secreted bacterial proteins released into the extracellular milieu? Curr Microbiol 2013, 67:688-695.

152. Prudovsky I, Tarantini F, Landriscina M, Neivandt D, Soldi R, Kirov A, Small D, Kathir KM, Rajalingam D, Kumar TK: Secretion without Golgi. J Cell Biochem 2008, 103:1327-1343.

153. Simon MC, Kusch J: Communicative functions of GPI-anchored surface proteins in unicellular eukaryotes. Crit Rev Microbiol 2013, 39:70-78.

154. Dorokhov YL, Skurat EV, Frolova OY, Gasanova TV, Ivanov PA, Ravin NV, Skryabin KG, Makinen KM, Klimyuk VI, Gleba YY, Atabekov JG: Role of the leader sequence in tobacco pectin methylesterase secretion. FEBS Lett 2006, 580:3329-3334.

155. De Groot PW, Ram AF, Klis FM: Features and functions of covalently linked proteins in fungal cell walls. Fungal Genet Biol 2005, 42:657-675.

156. Deising H, Rauscher M, Haug M: Differentiation and cell wall degrading enzymes in the obligately biotrophic rust fungus Uromyces viciae-fabae. Can J Bot 1995, 73:S624-S631.

157. Brunner PC, Torriani SF, Croll D, Stukenbrock EH, McDonald BA: Coevolution and life cycle specialization of plant cell wall degrading enzymes in a hemibiotrophic pathogen. Mol Biol Evol 2013, 30:1337-1347

158. Zhang XW, Jia LJ, Zhang Y, Jiang G, Li X, Zhang D, Tang WH: In planta stage-specific fungal gene profiling elucidates the molecular strategies of Fusarium graminearum growing inside wheat coleoptiles. Plant Cell 2012, 24:5159-5176

159. Willats WG, McCartney L, Mackie W, Knox JP: Pectin: cell biology and prospects for functional analysis. Plant Mol Biol 2001, 47:9-27.

160. Verhertbruggen Y, Marcus SE, Haeger A, Ordaz-Ortiz JJ, Knox JP: An extended set of monoclonal antibodies to pectic homogalacturonan. Carbohydr Res 2009, 344:1858-1862.
161. Mingora C, Ewer J, Ospina-Giraldo M: Comparative structural and functional analysis of genes encoding pectin methylesterases in Phytophthora spp. Gene 2014, 538:74-83.

162. Klosterman SJ, Subbarao KV, Kang S, Veronese P, Gold SE, Thomma BPHJ, Chen Z, Henrissat B, Lee Y-H, Park J, Garcia-Pedrajas MD, Barbara DJ, Anchieta A, de Jonge R, Santhanam P, Maruthachalam K, Atallah Z, Amyotte SG, Paz Z, Inderbitzin P, Hayes RJ, Heiman DI, Young S, Zeng Q, Engels R, Galagan J, Cuomo CA, Dobinson KF, Ma L-J: Comparative genomics yields insights into niche adaptation of plant vascular wilt pathogens. PLOS Pathog 2011, 7:e1002137.

163. Amselem J, Cuomo CA, van Kan JA, Viaud M, Benito EP, Couloux A, Coutinho PM, de Vries RP, Dyer PS, Fillinger S, Fournier E, Gout L, Hahn M, Kohn L, Lapalu N, Plummer KM, Pradier JM, Quevillon E, Sharon A, Simon A, ten Have A, Tudzynski B, Tudzynski P, Wincker P, Andrew M, Anthouard V, Beever RE, Beffa R, Benoit I, Bouzid O, et al: Genomic analysis of the necrotrophic fungal pathogens Sclerotinia sclerotiorum and Botrytis cinerea. PLoS Genet 2011, 7:e1002230.

164. Cooper RM, Longman D, Campbell A, Henry M, Lees PE: Enzymic adaptation of cereal pathogens to the monocotyledonous primary wall. Physiol Mol Plant Pathol 1988, 32:33-47.

165. Luna E, Pastor V, Robert J, Victor Flors V, Mauch-Mani B, Ton J: Callose deposition: A multifaceted plant defense response. Mol Plant Microbe Interact 2011, 24:183-193.

166. Ellinger D, Naumann M, Falter C, Zwikowics C, Jamrow T, Manisseri C, Somerville SC, Voigt CA: Elevated early callose deposition results in complete penetration resistance to powdery mildew in Arabidopsis. Plant Physiol 2013, 161:1433-1444.

167. Ham JH, Kim MG, Lee SY, Mackey D: Layered basal defenses underlie nonhost resistance of Arabidopsis to Pseudomonas syringae pv. phaseolicola. Plant J 2007, 51:604-616.

doi:10.1186/1471-2164-15-785

Cite this article as: Blackman et al: Bioinformatic characterisation of genes encoding cell wall degrading enzymes in the Phytophthora parasitica genome. BMC Genomics 2014 15:785.

\section{Submit your next manuscript to BioMed Central and take full advantage of:}

- Convenient online submission

- Thorough peer review

- No space constraints or color figure charges

- Immediate publication on acceptance

- Inclusion in PubMed, CAS, Scopus and Google Scholar

- Research which is freely available for redistribution 